\title{
Stress, strain, and B-type olivine fabric in the fore-arc mantle: Sensitivity tests using high-resolution steady-state subduction zone models
}

\author{
E. A. Kneller, ${ }^{1}$ P. E. van Keken, ${ }^{1}$ I. Katayama, ${ }^{2}$ and S. Karato ${ }^{2}$ \\ Received 3 June 2006; revised 17 October 2006; accepted 7 November 2006; published 17 April 2007.
}

[1] Shear-wave splitting observations at several subduction systems show trench-parallel fast directions in the fore-arc mantle. The presence of B-type olivine fabric in the mantle wedge may provide an explanation for this pattern of anisotropy under low-temperature and hydrated conditions. Sensitivity tests are shown that provide insights into the distribution and magnitude of B-type fabric using two-dimensional, highresolution, kinematic-dynamic subduction zone models. These models include a wet olivine rheology and a simulated aseismic creep zone in the fore-arc mantle with parameterized viscous coupling between the slab and mantle wedge. The calculated thermal structure is in reasonable agreement with heat flow observations and Q tomography for small amounts of coupling and moderate amounts of shear heating in the seismogenic and aseismic creep zones. These small amounts of viscous coupling give rise to a slowly flowing fore-arc mantle with thermal, stress, and strain conditions suitable for significant B-type fabric development. The minimum shear stress necessary to drive geologically significant flow in the predicted B-type region is sensitive to the magnitude of shear heating along the aseismic creep zone and ranges from less than 100 to $300 \mathrm{MPa}$. The minimum time required to generate sufficient finite strain for fabric development in the B-type region is around $10 \mathrm{Myr}$ depending on the amount of coupling and shear heating. The predicted distribution of olivine fabric is consistent with a pattern of shear wave anisotropy with trench-parallel fast polarization directions above the fore arc and a rapid rotation to trench-perpendicular in the arc and back arc.

Citation: Kneller, E. A., P. E. van Keken, I. Katayama, and S. Karato (2007), Stress, strain, and B-type olivine fabric in the fore-arc mantle: Sensitivity tests using high-resolution steady-state subduction zone models, J. Geophys. Res., 112, B04406, doi:10.1029/2006JB004544.

\section{Introduction}

[2] Trench-parallel shear-wave splitting is observed close to the trench in many subduction systems with suborthogonal convergence [Smith et al., 2001; Nakajima and Hasegawa, 2004; Anderson et al., 2004; Long and van der Hilst, 2005; Nakajima et al., 2006]. Several subduction systems also show a rotation to trench-perpendicular fast directions in the arc and back arc [Polet et al., 2000; Nakajima and Hasegawa, 2004; Long and van der Hilst, 2005; Nakajima et al., 2006]. This pattern of anisotropy is not explained by a model with two-dimensional (2-D) slab-driven flow and the most commonly observed olivine fabric, which produces a pattern of shear-wave splitting with fast vibration directions parallel to the flow direction. Recent experiments [Jung and Karato, 2001; I. Katayama and S. Karato, The effect of water

\footnotetext{
${ }^{1}$ Department of Geological Sciences, University of Michigan, Ann Arbor, Michigan, USA.

${ }^{2}$ Department of Geology and Geophysics, Yale University, New Haven, Connecticut, USA.
}

Copyright 2007 by the American Geophysical Union. 0148-0227/07/2006JB004544\$09.00 on low temperature rheology of olivine, submitted to Journal of Geophysical Research, 2007, hereinafter referred to as Katayama and Karato, submitted manuscript, 2007] show that at low temperatures and hydrated conditions the seismically fast directions of olivine crystals align subperpendicular to the shear direction and in the shear plane. This so-called B-type olivine fabric may explain trench-parallel shear-wave splitting with simple 2-D slab-induced cornerflow close to the trench where temperatures are low and stress may be relatively high [Jung and Karato, 2001; Karato, 2003] (Figure 1). The B-type fabric anisotropy hypothesis provides an explanation for trench-parallel shear-wave splitting without invoking relatively complex 3-D flow processes in the cold viscous nose of the mantle wedge.

[3] In previous work we predicted the distribution of Btype fabric with non-Newtonian thermal and stress models of subduction zones [Kneller et al., 2005]. The main conclusion of this work was that the fore-arc mantle is the best candidate for large volumes of peridotite with a dominance of B-type fabric over other fabrics (e.g., A-, C-, or E-type [Katayama et al., 2004]) (Figure 1). Kneller et al. [2005] implemented an ad hoc low-temperature creep 


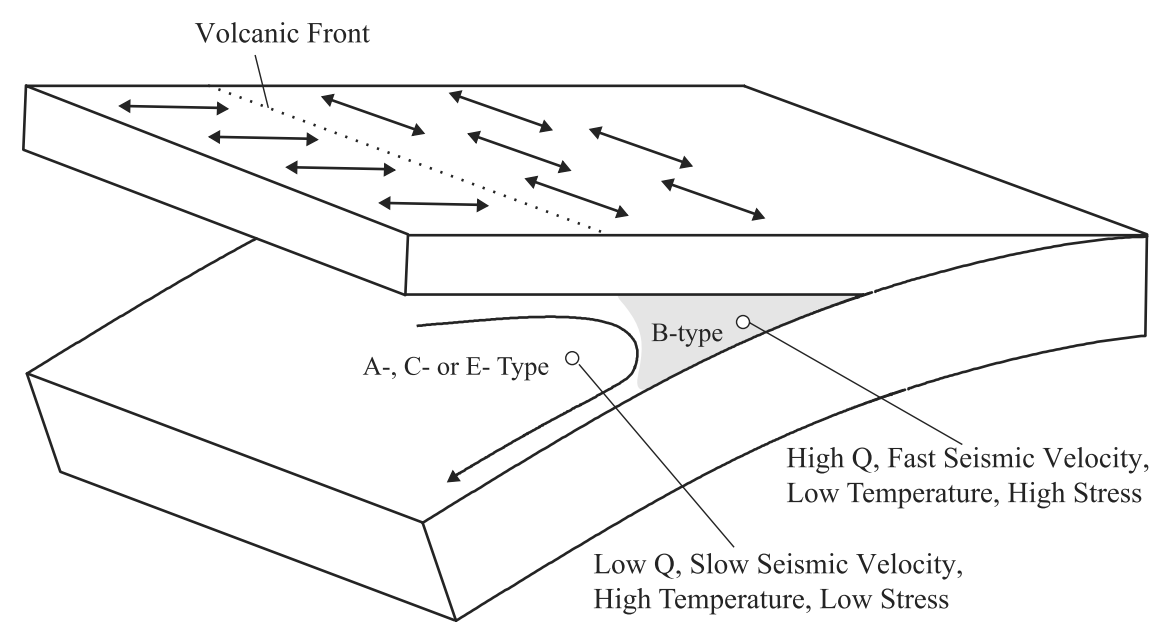

Figure 1. Diagram showing the shear-wave splitting pattern predicted by Kneller et al. [2005]. Conditions suitable for B-type fabric are predicted in the fore-arc mantle where high seismic quality (Q) and seismic velocity and low surface heat flow suggest low temperatures. A rapid transition is also predicted across the volcanic front from trench-parallel fast directions in the cold fore-arc mantle to trench-perpendicular in the hot arc and back-arc mantle.

law that did not include temperature dependence. In this work we improve the rheology of Kneller et al. [2005] by implementing an experimentally based low-temperature exponential creep law (Katayama and Karato, submitted manuscript, 2007). Other improvements included in the present work are finite strain calculations in the predicted B-type region and the addition of viscous dissipation in the heat equation. Finally, the distribution of fabric is predicted with a newly formulated theoretical model of olivine fabric transitions that is based on experiments and constrained by natural observations [Katayama and Karato, 2006]. These improvements allow more realistic quantification of the distribution and magnitude of B-type fabric and the magnitude of shear stress necessary to drive geologically significant deformation in the predicted B-type region.

\section{Viscous Coupling and the Thermal State of the Fore-Arc Mantle}

[4] A variety of observations suggest that temperatures in the fore-arc mantle are low relative to the arc and back-arc mantle. Examples include high seismic velocity [Zhao et al., 1995; Tsumura et al., 2000; Nakajima and Hasegawa, 2004], low attenuation [Sacks, 1984; Takanami et al., 2000; Stachnik et al., 2004], and low surface heat flow [Furukawa and Uyeda, 1989; Von Herzen et al., 2001; Okubo et al., 2005]. Several workers have investigated the role of reduced viscous coupling between the slab and mantle wedge in producing this cold nose of the mantle wedge [Furukawa, 1993; Conder, 2005; Kneller et al., 2005]. These studies show that when a temperature-dependent rheology is implemented, the slab and fore-arc mantle must be decoupled down to a depth ranging from 70 to $100 \mathrm{~km}$ in order to produce a thermal structure that agrees with heat flow observation and seismic attenuation.

[5] A variety of approaches have be used to decouple the slab and fore-arc mantle in viscous flow models: (1) the implementation of a free-slip boundary condition along the surface of the slab [Furukawa, 1993], (2) locking computational nodes above the slab where brittle processes are predicted to dominate deformation [Conder, 2005], (3) reducing viscosity in the slab-wedge interface [Billen and Gurnis, 2001], and (4) reducing the magnitude of the velocity boundary condition [Kneller et al., 2005]. Decoupling may be caused by aseismic creep down-dip of the seismogenic zone. With this scenario, deformation is dominated by brittle processes and shear stress exerted by the subducting slab may induce a small component of longtimescale viscous flow. Evidence for aseismic creep comes from periodic slow events and persistent tremor down-dip of the seismogenic zone [Miller et al., 2001; Obara, 2002; Rogers and Dragert, 2003]. Another possibility is where decoupling is caused by shear localization associated with the presence of weak minerals such as serpentine and talc [Peacock and Hyndman, 1999; Hyndman and Peacock, 2003]. The effect of both a layer of weak minerals and brittle fault is to localize deformation close to the slabwedge interface. Both of these mechanisms of decoupling give rise to slower particle motion in the mantle wedge relative to a fully coupled case (Figure 2).

[6] Modeling these decoupling processes in a self-consistent manner is difficult and requires better experimental constraints. However, we can simulate the effect of both processes with a parameterized velocity boundary condition (Figures 2 and 3). This is accomplished by reducing the magnitude of the velocity boundary condition $\left(V_{\text {red }}\right)$ at the surface of the slab to a small percentage of the convergence velocity $\left(V_{\text {slab }}\right)$ [Kneller et al., 2005] (Figure 3). The parameter $V_{\text {red }}$ is a proxy for viscous coupling in the partially decoupled zone. We denote the amount of coupling in with $\phi$, which is defined as

$$
\phi=\frac{V_{\text {red }}}{V_{\text {slab }}}
$$

[7] The partially coupled zone is prescribed down to a depth denoted by $D$. $V_{\text {red }}$ is ramped up in a linear manner over $15 \mathrm{~km}$ to $V_{\text {slab }}$ at $D$. This transition from partial to full 


\section{(a) Full Coupling}

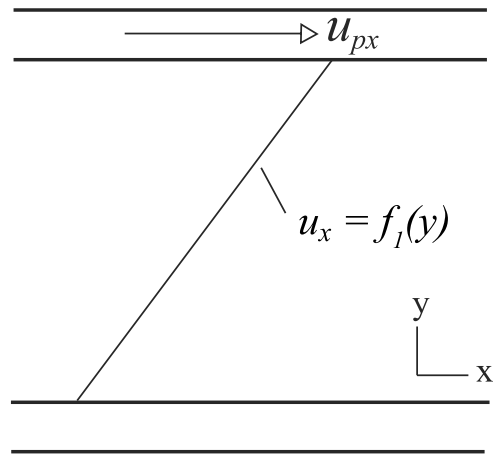

(c) Partial Coupling: Weak layer

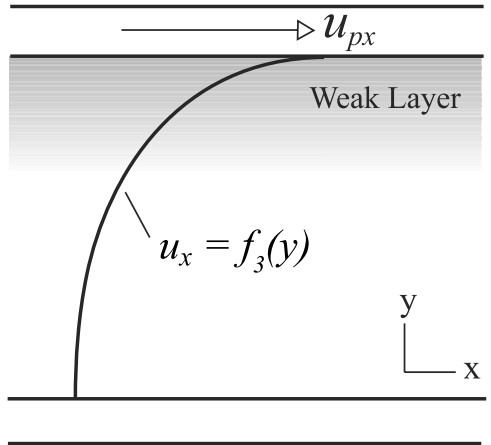

(b) Partial Coupling: Fault

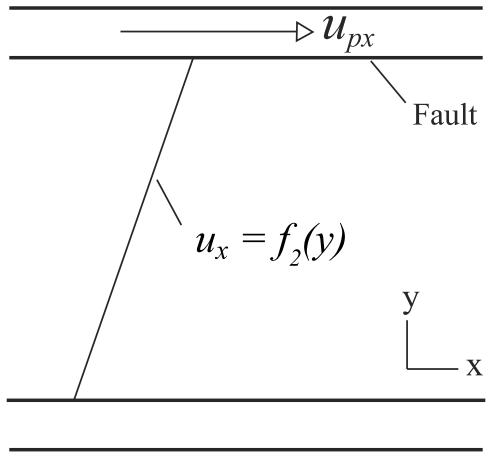

Figure 2. Different types of decoupling in a viscous fluid undergoing simple shear between two plates. The upper plate moves to the right with velocity $u_{p x}$ while the bottom plate is stationary. Several types of coupling are shown: (a) a case with full coupling, (b) partial coupling caused by localized cold temperatures and brittle deformation between the fluid and upper plate (e.g., aseismic creep zone), and (c) partial coupling associated with a layer of relatively weak material (e.g., serpentinite) and shear localization. At the cold slab-wedge interface both brittle deformation and the formation of weak minerals may occur giving rise to both types of decoupling (Figure s $2 b$ and 2c). Note that the net effect of both types of decoupling is to reduce the velocity magnitude in the core of the fluid. We simulate decoupling by reducing the magnitude of the velocity boundary condition at the slab-wedge interface.

viscous coupling denotes either the brittle-to-ductile transition or the transition to stronger boundary layer materials. The maximum value of $D$ is constrained by the location of the volcanic arc below which hot mantle material must be supplied in order to sustain temperatures sufficient for flux melting. This maximum depth ranges from 70 to $170 \mathrm{~km}$ with an average of around $105 \mathrm{~km}$ [England et al., 2004; Syracuse and Abers, 2006].

\section{Modeling Approach}

\subsection{Thermal and Fluid Dynamic Models}

[8] We implement a kinematic dynamic approach where the slab and overriding plate are kinematically described and the equations governing fluid flow are solved only in the mantle wedge [Davies and Stevenson, 1992; Peacock and Wang, 1999; van Keken et al., 2002; Kneller et al., 2005] (Figure 3). Fluid flow in the mantle wedge is driven by the slab and governed by the conservation of momentum and mass for an incompressible infinite Prandtl number fluid without body forces. The conservation of momentum is expressed as

$$
-\nabla P+\nabla \cdot(\eta \dot{\boldsymbol{\epsilon}})=0
$$

where $\dot{\epsilon}$ is the strain rate tensor, $\eta$ is effective viscosity, and $P$ is dynamic pressure. The conservation of mass is expressed as

$$
\nabla \cdot \mathbf{u}=0
$$

where $\mathbf{u}$ is velocity. No-slip boundary conditions are applied along the base of the overriding plate and surface of the slab. As discussed above, the magnitude of the velocity boundary condition along the surface of the slab is variable. The direction of velocity boundary condition is parallel to the surface of the slab. Velocity at the base of the overriding plate is set equal to zero. A stress-free (i.e., zero normal stress) inflow-outflow boundary condition is implemented along the right-hand boundary of the mantle wedge (Figure 3 ). The nonlinear exponential stress dependence of $\eta$ in equation (2) requires a special iterative procedure, which is described in Appendix A. A viscosity maximum of $10^{28}$ $\mathrm{Pa}$ is used in the models presented in this study.

[9] The conservation of energy takes the form of the steady-state advection-diffusion equation

$$
\rho c_{p}(\mathbf{u} \cdot \nabla) T=\nabla \cdot(k \nabla T)+q_{\text {rad }}+q_{\text {dissi }}+q_{\text {fault }}
$$




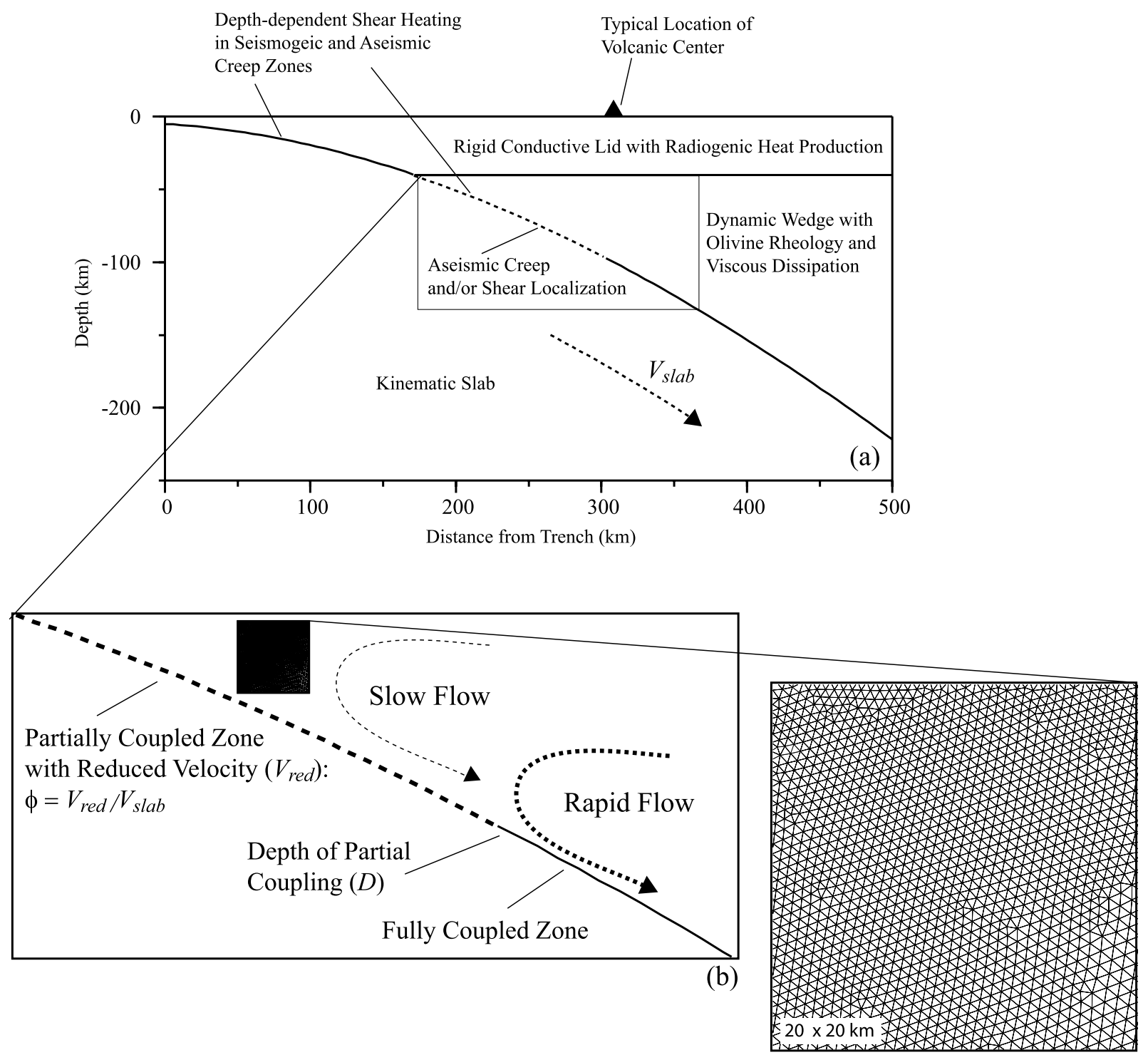

(c)

Figure 3. (a) Model domain and kinematic dynamic setup. The partially coupled zone is denoted with a dashed line. (b) In this zone, the magnitude of the velocity boundary condition is reduced $\left(V_{\text {red }}\right)$ to a small fraction $(\phi)$ of the convergence velocity $V_{\text {slab }}$. The depth of the partially coupled zone is denoted with $D$. (c) The model domain is discretized into a high resolution finite-element mesh composed of linear triangles. Resolution in the fore-arc mantle is $500 \mathrm{~m}$.

where $k$ is thermal conductivity, $T$ is temperature, $c_{p}$ is specific heat, $\rho$ is density, $q_{\text {rad }}$ is radiogenic heat production in the crust, $q_{\text {dissi }}$ is viscous dissipation in the viscous mantle wedge, and $q_{\text {fault }}$ is frictional shear heating associated with fault slip in the seismogenic and aseismic creep zones. In the slab the magnitude of $\mathbf{u}$ in equation (4) is set equal to the convergence velocity at the trench. The direction of $\mathbf{u}$ is parallel to the surface of the slab. The magnitude of $\mathbf{u}$ in the overriding plate is zero.

[10] Viscous dissipation is defined as

$$
q_{d i s s i}=\dot{\epsilon} \sigma
$$

where $\dot{\epsilon}$ is the second invariant of the strain rate tensor and $\sigma$ is the second invariant of the stress tensor. $\sigma$ is obtained by solving the following nonlinear equation at every computational node:

$$
\sigma-\dot{\epsilon} \eta=0
$$

where $\eta$ is a composite law described in the next section and $\dot{\epsilon}$ is obtained from derivatives of the velocity field. Note that $\eta$ is a function of $\dot{\epsilon}$ which gives rise to the nonlinearity. Viscous dissipation is calculated after each steady-state iteration using $\dot{\epsilon}$ calculated with an updated velocity field. A more complete description of this iterative procedure can be found in Appendix A.

[11] The viscous flow models presented in this work do not include short-timescale brittle discontinuous processes. Heating associated with fault slip in the seismogenic and 
aseismic creep zones cannot be modeled self-consistently. We explore the effects of frictional heating with a delta function heat source

$$
q_{\text {fault }}=q_{\text {fault,mag }} \delta\left(\mathbf{x}_{\text {interface }}\right)
$$

where $q_{\text {fault,mag }}$ is the magnitude of shear heating, $\mathbf{x}_{\text {interface }}$ is the position of the shear heating zone and $\delta$ has the dimensions $\mathrm{m}^{-1}$ [van Keken et al., 2002]. The magnitude of shear heating $q_{\text {fault,mag }}$ varies with depth down to $70 \mathrm{~km}$ as described by

$$
q_{\text {fault }, \text { mag }}=S z
$$

where $S$ is the shear heating gradient $\left(\mathrm{mW} / \mathrm{m}^{2} / \mathrm{km}\right)$ and $z$ is depth (in kilometers). Below $70 \mathrm{~km}, q_{\text {fault,mag }}$ decreases in a linear manner to 0 at a depth of $100 \mathrm{~km}$. Shear heating is set equal to zero below $100 \mathrm{~km}$. The magnitude of shear heating is related to frictional shear stress acting on a fault as follows

$$
q_{\text {fault }, \text { mag }}=\tau V
$$

where $\tau$ is shear stress and $V$ is the relative velocity across the fault plane. This expression leads to the following relationship between $S$ and the effective coefficient of friction $c_{\text {fric }}$ :

$$
c_{\text {fric }}=\frac{S}{\rho g V}
$$

where $\rho$ is density and $g$ is gravitational acceleration. We use a maximum value of $S$ equal to 5 , which corresponds to $c_{\text {fric }}=0.053$ for the convergence velocity used in this study $(V=9.1 \mathrm{~cm} / \mathrm{yr})$. This maximum value of $c_{\text {fric }}$ is consistent with estimates based on stress models for the Japan subduction system [Wang and Suyehiro, 1999].

[12] The finite element package SEPRAN [Cuvelier et al., 1986] is used to obtain numerical solutions of governing equations and for mesh generation. The model domain is discretized into linear triangles with a resolution that ranges from 0.5 to $1 \mathrm{~km}$ (Figure 3 ). For the solution of equations (2) and (3) we use linear Taylor-Hood triangles [Cuvelier et al., 1986]. For the solution of equation (4) we use the streamline upwind Petrov-Galerkin method [van Keken et al., 2002]. The resulting systems of equations are solved using the Bi-CGStab iterative method [van der Vorst, 1992].

\subsection{Finite Strain}

[13] Finite strain is calculated in 30,000 particles using the velocity field obtained by solving equations (2)-(4). This velocity field is interpolated onto a uniform grid composed of quadratic elements with $1 \mathrm{~km}$ resolution. The direction and magnitude of maximum and minimum principle stretch axes of finite strain ellipses are obtained by numerically solving the following equation using a fourthorder Runge Kutta scheme:

$$
\frac{\partial}{\partial t} \mathbf{F}=\mathbf{L} \cdot \mathbf{F}
$$

where $\mathbf{L}$ is the velocity gradient tensor and and $\mathbf{F}$ is the deformation gradient tensor [McKenzie, 1979; Spencer, 1980]. The velocity gradient tensor is defined as

$$
\mathbf{L}=\left[\begin{array}{l}
\frac{\partial v_{x}}{\partial x} \frac{\partial v_{x}}{\partial y} \\
\frac{\partial v_{y}}{\partial x} \frac{\partial v_{y}}{\partial y}
\end{array}\right]
$$

where $v_{x}$ and $v_{y}$ are velocity components in the $x$ and $y$ directions, respectively. The deformation gradient tensor is defined as

$$
\mathbf{F}=\left[\begin{array}{cc}
\frac{\partial s_{x}}{\partial x}+1 & \frac{\partial s_{x}}{\partial y} \\
\frac{\partial s_{y}}{\partial x} & \frac{\partial s_{y}}{\partial y}+1
\end{array}\right]
$$

where $s_{x}$ and $s_{y}$ are components of displacement in the $x$ and $y$ directions. The tensor $\mathbf{F}$ relates a particles postdeformational position $\left(x_{f}, y_{f}\right)$ to its initial position $\left(x_{o}, y_{o}\right)$ excluding rigid translation. In order to calculate finite strain, $\mathbf{F}$ must be related to the left Cauchy-Green tensor $\mathbf{B}$

$$
\mathbf{B}=\mathbf{F} \cdot \mathbf{F}^{T}
$$

[14] The eigenvectors of $\mathbf{B}$ are the principle stretch directions. The magnitudes of the principle stretch axes of the finite strain ellipse are equal to the square roots of the eigenvalues of B [Spencer, 1980]. Particles are traced throughout the entire mantle wedge and have an initial spacing of $1 \mathrm{~km}$. Particles that are transported outside of the model domain are reinjected at the inflow boundary and have finite strain set equal to zero.

\section{Rheological Model}

[15] We are primarily concerned with deformation in the shallow mantle wedge where temperatures are low, conditions are most likely wet, and olivine is assumed to be the dominant mineral species. Therefore we implement an olivine rheology with experimentally based wet laws for exponential creep, power-law creep, and diffusion creep. In the following rheological equations symbols for a particular creep mechanism, denoted by subscript mech, have the following meaning: $\dot{\epsilon}_{m e c h}$ is strain rate, $A_{\text {mech }}$ is a preexponential constant, $E_{\text {mech }}$ is activation energy, and $V_{\text {mech }}$ is activation volume. Rheological parameters are shown in Table 1. Temperature, lithostatic pressure, and shear stress are denoted by $T, P$, and $\sigma$, respectively.

[16] The wet exponential creep law (Katayama and Karato, submitted manuscript, 2007) takes the following form:

$$
\begin{aligned}
\dot{\epsilon}_{\text {expo }}= & A_{\text {expo }} \sigma^{2}\left[\exp \left(-\frac{\left(E_{\text {expo }}+P V_{\text {expo }}\right)}{R T}\left(1-\left(\frac{\sigma}{\sigma_{p}}\right)^{p}\right)^{q}\right)\right. \\
& \left.-\exp \left(-\frac{\left(E_{\text {expo }}+P V_{\text {expo }}\right)}{R T}\left(1+\left(\frac{\sigma}{\sigma_{p}}\right)^{p}\right)^{q}\right)\right]
\end{aligned}
$$

where $\sigma_{p}$ is Peierls stress and $p$ and $q$ are constants. Equation (15) takes both forward (first exponential term) and backward motion (second exponential term) of dislocations into account (Katayama and Karato, submitted 
Table 1. Wet Rheological Parameters

\begin{tabular}{lllc}
\hline \multicolumn{1}{c}{ Symbol } & \multicolumn{1}{c}{ Description } & Source \\
\hline$A_{\text {expo }}$ & Constant & $10^{-3.2} \mathrm{~s}^{-1} \mathrm{~Pa}^{-2}$ & 1 \\
$\sigma_{p}, \mathrm{MPa}$ & Peierls stress & 3030 & 1 \\
$E_{\text {expo }}{ }^{\mathrm{b}} \mathrm{kJ} / \mathrm{mol}$ & Activation energy & 470 & 2 \\
$V_{\text {expo }} \mathrm{b} \mathrm{cm}^{3} / \mathrm{mol}$ & Activation volume & 24 & 3 \\
$q$ & Constant & 2 & 1 \\
$p$ & Constant & 1 & 1 \\
$A_{\text {power }}{ }^{\mathrm{c}}$ & Constant & $10^{-10.2} \mathrm{~s}^{-1} \mathrm{~Pa}^{-4.2}$ & 3 \\
$E_{\text {power }}, \mathrm{kJ} / \mathrm{mol}$ & Activation energy & 470 & 2 \\
$V_{\text {power }}, \mathrm{cm}^{3} / \mathrm{mol}$ & Activation volume & 24 & 3 \\
$n$ & Stress exponent & 3.0 & 2 \\
$A_{\text {diff }}^{\mathrm{c}}$ & Constant & $10^{-15.84} \mathrm{~s}^{-1} \mathrm{~Pa}^{-2.1} \mathrm{~m}^{3}$ & 4 \\
$E_{\text {diff }}, \mathrm{kJ} / \mathrm{mol}$ & Activation energy & 395 & 4 \\
$V_{\text {diff; }}, \mathrm{cm}^{3} / \mathrm{mol}$ & Activation volume & 20 & 4 \\
$m$ & Grain size exponent & 3.0 & 4 \\
\hline
\end{tabular}

${ }^{\mathrm{a}}$ References are as follows: 1 is Katayama and Karato [2006a], 2 is $\mathrm{Mei}$ and Kohlstedt [2000b], 3 is Karato and Jung [2003], and 4 is Mei and Kohlstedt [2000a].

${ }^{\mathrm{b}}$ Parameters are from the power-law creep [Katayama and Karato, 2006a].

manuscript, 2007). Forward motion dominates at high-stress conditions, whereas backward motion becomes important at low shear stress. The wet power-law creep equation [Karato, 2003] is defined as

$$
\dot{\epsilon}_{\text {power }}=A_{\text {power }} \exp \left[-\frac{\left(E_{\text {power }}+P V_{\text {power }}\right)}{R T}\right] \sigma^{n}
$$

where $n$ is the stress exponent. Finally, wet diffusion creep [Mei and Kohlstedt, 2000a] is defined by

$$
\dot{\epsilon}_{\text {diff }}=A_{\text {diff }} d^{-m} \exp \left[-\frac{\left(E_{\text {diff }}+P V_{\text {diff }}\right)}{R T}\right] \sigma
$$

where $d$ is grain size and $m$ is the grain size exponent.

[17] Parameters for (15) (Table 1) are from recent wet deformation experiments on olivine aggregates performed at relatively low temperatures $\left(1000-1100^{\circ} \mathrm{C}\right)$ and high strain rates (Katayama and Karato, submitted manuscript, 2007). These experiments show that water saturated conditions cause a reduction of $\sigma_{p}$ by a factor of two to three and a significant decrease in strength at low temperatures. Rheological parameters for equations (15) and (16) were obtained from experiments performed at pressures ranging from 1 to $2 \mathrm{GPa}$, values that are close to pressures within the fore-arc and arc mantle [Karato, 2003; Katayama and Karato, submitted manuscript, 2007]. The wet rheological laws are defined for a fixed water fugacity equal to $12,097 \mathrm{MPa}$, which corresponds to $T=1000^{\circ} \mathrm{C}, P=2 \mathrm{GPa}$, and a concentration of hydrogen point defects of approximately $1000 \mathrm{ppm} \mathrm{H/Si}$. These conditions may be representative of those found in the fore-arc and arc mantle of subduction zones. A deformation mechanism map for the wet olivine rheology implemented in this study is shown in Figure 4. We use a simplified rheological description where the effects of dynamic recrystallization are not taken into account and a constant grain size of $1 \mathrm{~mm}$ is used.

[18] Deformation is accommodated by the motion of dislocations with both exponential and power-law creep.
The motion of dislocations is primarily controlled by dislocation glide with exponential creep and climb with power-law creep. If deformation occurs primarily by dislocation processes, the rheological law will either take the form of exponential or power-law creep (Katayama and Karato, submitted manuscript, 2007). This is implemented with the following equation

$$
\dot{\epsilon}_{\text {disloc }}=\max \left(\dot{\epsilon}_{\text {power }}, \dot{\epsilon}_{\text {expo }}\right)
$$

where $\dot{\epsilon}_{\text {disloc }}$ is strain rate associated with dislocation processes, $\dot{\epsilon}_{\text {power }}$ is strain rate of power-law creep, and $\dot{\epsilon}_{\text {expo }}$ is strain rate of exponential creep. Dislocation and diffusion processes occur in parallel

$$
\dot{\epsilon}_{t o t}=\dot{\epsilon}_{d i s l o c}+\dot{\epsilon}_{d i f f}
$$

where $\dot{\epsilon}_{t o t}$ is the total strain rate. The effective viscosity in (2) is described by a composite law defined by

$$
\eta_{\text {comp }}=\frac{\sigma}{\dot{\epsilon}_{t o t}}
$$

which can be expressed as a geometric mean

$$
\eta_{\text {comp }}=\left(\frac{1}{\eta_{\text {disloc }}}+\frac{1}{\eta_{\text {diff }}}\right)^{-1}
$$

where

$$
\eta_{\text {disloc }}=\min \left(\frac{\sigma}{\dot{\epsilon}_{\text {expo }}}, \frac{\sigma}{\dot{\epsilon}_{\text {power }}}\right)
$$

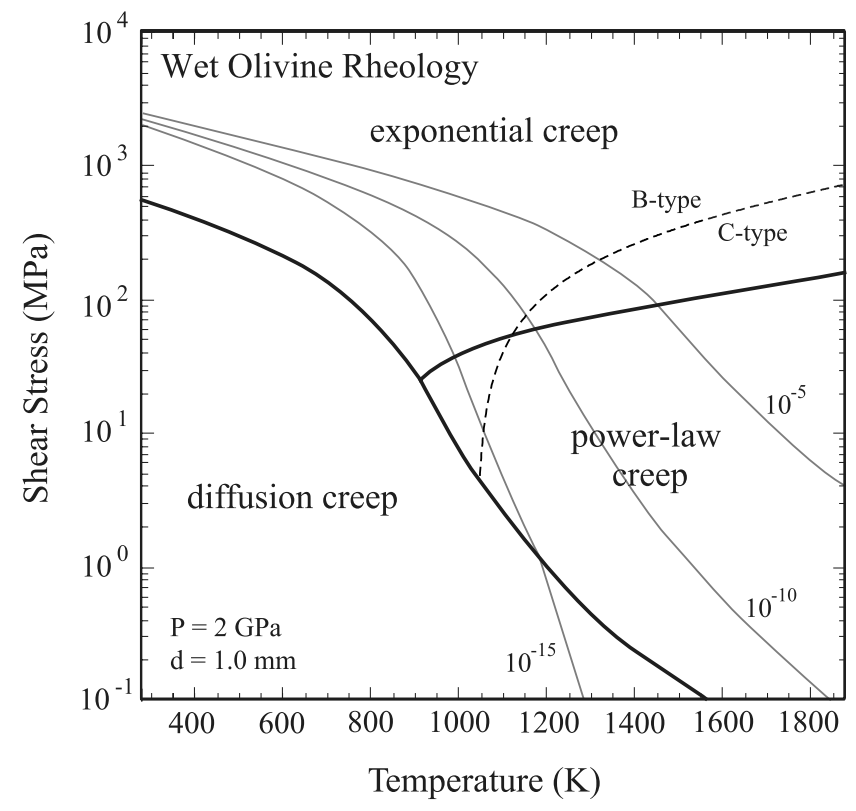

Figure 4. Deformation mechanism map [Katayama and Karato, 2006a] for the wet olivine rheology implemented in the viscous flow models presented in this work. The B-C transition used in the models presented in this work is denoted with a dashed line [Katayama and Karato, 2006b]. 


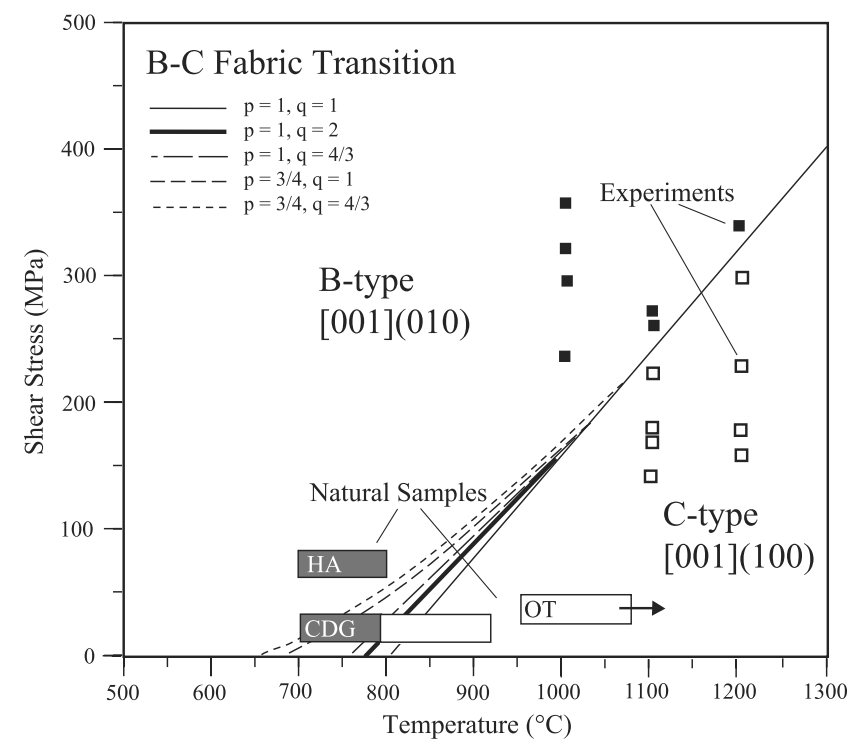

Figure 5. Olivine fabric map showing experimentally observed B-type (black squares) and C-type (open squares) fabrics, and naturally observed B-type (gray rectangles) and C-type fabrics (white rectangles) [Katayama and Karato, 2006b]. Natural samples come from Otroy island, Norway (OT) [Katayama et al., 2005], Higashi-Akaishi-Yama, Japan (HA) [Mizukami et al., 2004], and Cima di Gagnone, central Alps (CDG) [Frese et al., 2003; Skemer et al., 2006]. The curves denote theoretical B-C transitions for different rheological parameters [Katayama and Karato, 2006b]. The thick black curve denotes the B-C transition used in this study.

and

$$
\eta_{d i f f}=\frac{\sigma}{\dot{\epsilon}_{\text {diff }}}
$$

\section{Olivine Fabric Model}

[19] Most olivine fabric types observed in nature and the laboratory produce a pattern of shear-wave splitting with a fast polarization direction that aligns parallel to flow direction [Jung and Karato, 2001]. The dry endmember of this group, A-type, is associated with slip on $[100](010)$ and is the most commonly observed variety. The wet end-member, C-type, involves slip on [001](100) and has been observed at convergent tectonic settings [Mockel, 1969; Katayama et al., 2005]. B-type fabric is associated with slip on [001](010). This fabric is of interest because it produces a pattern of shear-wave splitting with a fast polarization direction that aligns perpendicular to the flow direction. B-type fabric has been observed in the laboratory under hydrated conditions at high shear stress [Jung and Karato, 2001; Katayama and Karato, 2006; Katayama and Karato, submitted manuscript, 2007]. B-type fabric has also been observed in the Higashi Akaishi peridotite body, Japan [Mizukami et al., 2004], and Almklovdalen massif, Norway [Cordellier et al., 1981]. In accordance with the wet (1000 ppm H/Si) rheological law implemented in this work, fabric type is assumed to be either B- or C-type.

[20] The transition from C- to B- type fabric is associated with a transition from easy slip on [001](100) to [001](010) [Katayama and Karato, 2006]. Theoretical considerations show that exponential rheological laws for these slip systems can be set equal to each other to derive an equation describing the fabric transition in terms of shear stress and temperature [Katayama and Karato, 2006]. This theory shows that the transition from B- to C-type and other fabrics is approximately linear with a positive slope of stress verses temperature (Figures 4 and 5). The theoretical B-C boundary is constrained by experiments [Jung and Karato, 2001; Katayama and Karato, submitted manuscript, 2007] and natural observations of B- and C-type fabrics [Frese et al., 2003; Mizukami et al., 2004; Katayama et al., 2005; Skemer et al., 2006] (Figure 5). Extrapolation from experimental to mantle conditions using this linear transition shows that the transition temperature between $\mathrm{B}$ - and C-type fabric is around $650-800^{\circ} \mathrm{C}$ depending on rheological parameters (Katayama and Karato, submitted manuscript, 2007). According to Katayama and Karato [2006], the transition conditions between the B- and C-type fabrics can be expressed as

$$
T_{\text {trans }}=\frac{H_{c}}{R \log \frac{A_{c}}{A_{b}}}\left(1-\left(\frac{\sigma_{\text {trans }}}{\sigma_{p c}}\right)^{p}\right)^{q}-\frac{H_{b}}{R \log \frac{A_{c}}{A_{b}}}\left(1-\left(\frac{\sigma_{\text {trans }}}{\sigma_{p b}}\right)^{p}\right)^{q}
$$

where $T_{\text {trans }}$ is the transition temperature, $\sigma_{\text {trans }}$ is the transition stress, subscript $\mathrm{c}$ denotes the C-type slip system, subscript $\mathrm{b}$ denotes the B-type slip system, $H$ is activation energy, $\sigma_{p}$ is Peierls stress, $R$ is the gas constant, and $A, p$, and $q$ are constants. The effects of pressure are small in the pressure range of the fore-arc and arc mantle $(<4 \mathrm{GPa})$. The specific values of parameters are not well constrained but the uncertainties in these values do not significantly change the conditions for the fabric transition (see Figure 5). In the present calculation we use the following values: $\log \frac{A_{1}}{A_{2}}=5.81, H_{1}=543 \mathrm{~kJ} / \mathrm{mol}, H_{2}=$ $493 \mathrm{~kJ} / \mathrm{mol}, \sigma_{p 1}=4480 \mathrm{MPa}, \sigma_{p 2}=3120 \mathrm{MPa}, p=1$, and $q=2$. This set of parameters gives rise to a B-C transition denoted by the dashed curve in Figure 4 and thick black curve in Figure 5.

[21] The criteria for fabric development used in the models presented in this work also requires the dominance of either power-law or exponential creep over diffusion creep and the accumulation of sufficient finite strain. We define the magnitude of finite strain $(\zeta)$ as $\log \left(\frac{a}{b}\right)$, where $a$ is the magnitude of the maximum stretch axis and $b$ is the magnitude of the minimum stretch axis. Experiments and theoretical calculations suggest that $\zeta$ must be around 0.3 to generate a seismologically significant fabric [Ribe, 1992; Zhang et al., 2000; Lassak et al., 2006]. Finite strain is built up by both shear and longitudinal elongation. The former will primarily contribute to the formation of the B-type fabric. On the basis of the instantaneous velocity gradients we predict that a significant amount (but not all) of the finite strain is caused by shear, and we 
$D=70 \mathrm{~km} ; \phi=2 \% ; S=0 \mathrm{~mW} / \mathrm{m}^{2} / \mathrm{km}\left(c_{\text {fric }}=0\right)$

(a) Fabric Type

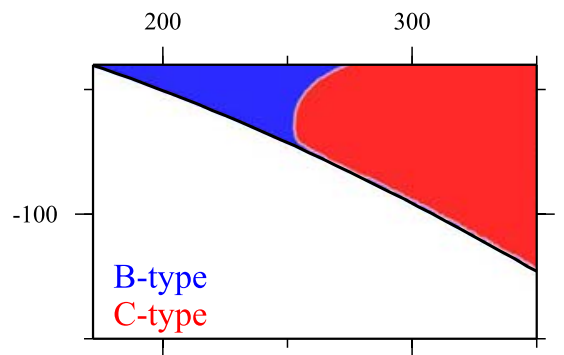

(b) $\log \varepsilon_{\mathrm{T}}\left(\mathrm{s}^{-1}\right)$
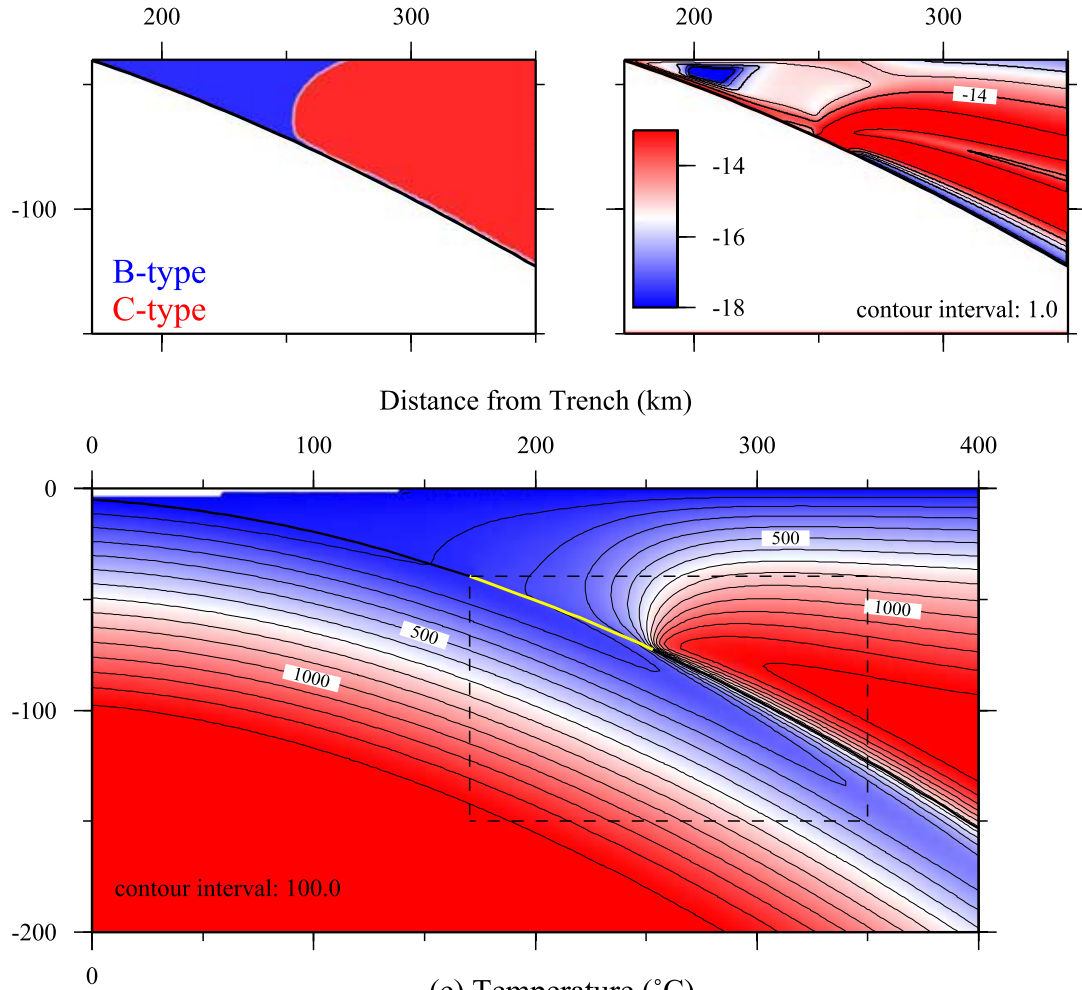

300

200

$0-100$

Distance from Trench $(\mathrm{km})$
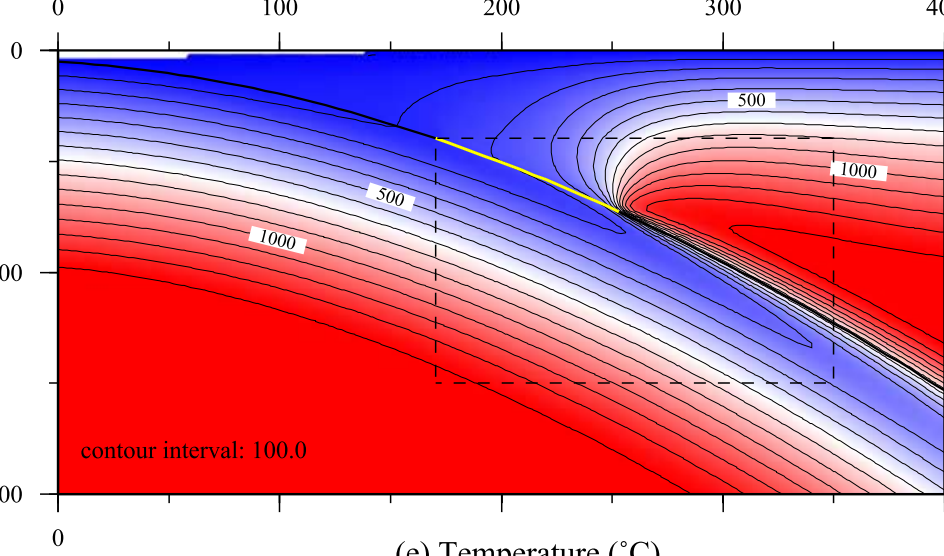

0

(e) Temperature $\left({ }^{\circ} \mathrm{C}\right)$ (c) $\log |\mathbf{u}|(\mathrm{cm} / \mathrm{yr})$

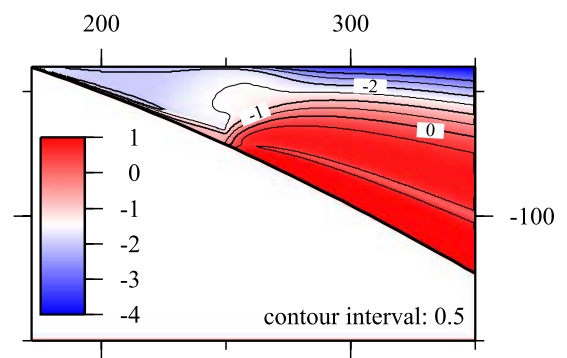

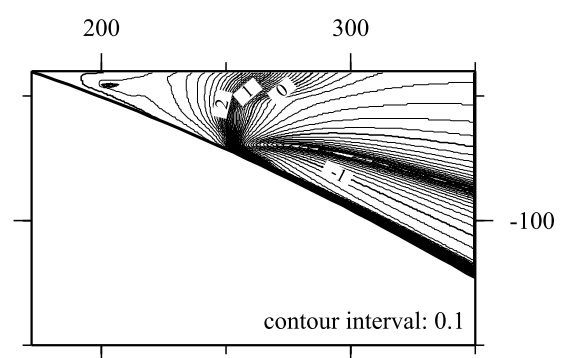

Figure 6. (a) Calculated fabric type, (b) strain rate, (c) magnitude of particle velocity, (d) shear stress, and (e) temperature for a model with $D=70 \mathrm{~km}, \phi=2 \%$, and $S=0 \mathrm{~mW} / \mathrm{m}^{2} / \mathrm{km}$. The zone with reduced velocity boundary condition is denoted with a yellow line.

will use the finite strain directions and magnitudes as indicative of B-type fabric.

\section{Results}

\subsection{Fluid Dynamic and Thermal Calculations}

[22] Shear-wave splitting observations at the Honshu subduction system show trench-parallel fast polarization above the fore arc and an abrupt rotation to trench-perpendicular above the back arc [Nakajima and Hasegawa, 2004]. This transition in polarization direction is accompanied by a transition from large seismic velocity (low temperature) in the fore-arc mantle to relatively low seismic velocity in the arc and back-arc mantle (high temperature) [Nakajima and Hasegawa, 2004]. Furthermore, three-dimensional flow is unlikely in this system because convergence is orthogonal to suborthogonal. These observations are consistent with the B-type fabric hypothesis suggesting that the pattern of shear-wave splitting is controlled by a transition from Bto C-type fabric across the volcanic arc. We explore the sensitivity of the distribution and magnitude of B-type fabric to important parameters using a model of the Honshu subduction system (Figure 3).

[23] Subduction zone geometry is almost identical to Peacock and Hyndman [1999] and van Keken et al. [2002] except that the slab surface is defined by a thirdorder polynomial (Figure 3). Convergence velocity is set equal to $9.1 \mathrm{~cm} / \mathrm{yr}$ and the age of incoming lithosphere is
130 Myr. Conductivity $k$ is equal to $2.5 \mathrm{~W} / \mathrm{m} / \mathrm{K}$ in a $40 \mathrm{~km}$ thick overriding plate and $3.1 \mathrm{~W} / \mathrm{m} / \mathrm{K}$ in the slab and mantle wedge. We set specific heat equal to $1250 \mathrm{~J} / \mathrm{kg} / \mathrm{K}$ and density equal to $3300 \mathrm{~kg} / \mathrm{m}^{3}$. Radiogenic heat production $q_{\text {rad }}$ in the overriding plate is $1.3 \mu \mathrm{W} / \mathrm{m}^{3}$ from 0 to $15 \mathrm{~km}$ (upper crust) and $0.27 \mu \mathrm{W} / \mathrm{m}^{3}$ from 15 to $30 \mathrm{~km}$ (lower crust).

[24] Thermal structure, shear stress required to drive geologically significant deformation, and B-type conditions are primarily controlled by three parameters: (1) the depth of the transition from partial to full viscous coupling $D$, (2) the magnitude of the velocity boundary condition along the aseismic creep zone, which controls the amount of viscous accommodation $\phi$, and (3) the magnitude of shear heating gradient $S$. We begin by showing model results with end-member values for $D$ and intermediate $\phi$.

[25] Figure 6 shows a case with $D=70 \mathrm{~km}, \phi=2 \%$, and no shear heating. Thermal (Figure 6e) and stress conditions (Figure 6d) are suitable for B-type fabric (Figure 6a) in the fore-arc mantle extending $100 \mathrm{~km}$ from the corner point. The boundary between B- and C-type fabric is approximately vertical and the maximum vertical thickness of the B-type region is $30 \mathrm{~km}$. In the B-type region, particle velocity is low $\left(10^{-1}\right.$ to $10^{-2} \mathrm{~cm} / \mathrm{yr}$ (Figure 6c) while velocity gradients are relatively high and deformation occurs at a geologically significant rate $\left(10^{-16}\right.$ to $\left.10^{-15} \mathrm{~s}^{-1}\right)$ (Figure $6 \mathrm{~b}$ ). Particle velocity in the hot core of the mantle wedge is one to two orders of magnitude larger and 
$D=100 \mathrm{~km} ; \phi=2 \% ; S=0 \mathrm{~mW} / \mathrm{m}^{2} / \mathrm{km}\left(c_{\text {fric }}=0\right)$ (a) Fabric Type

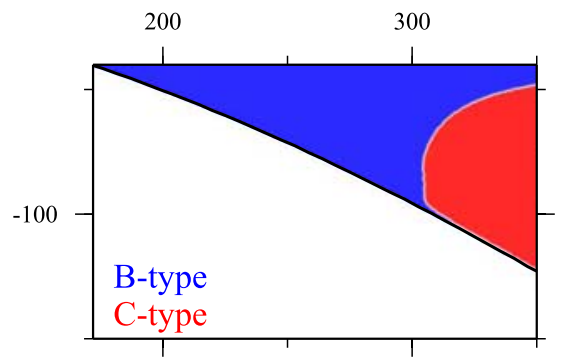

(b) $\log \varepsilon_{\mathrm{T}}\left(\mathrm{s}^{-1}\right)$

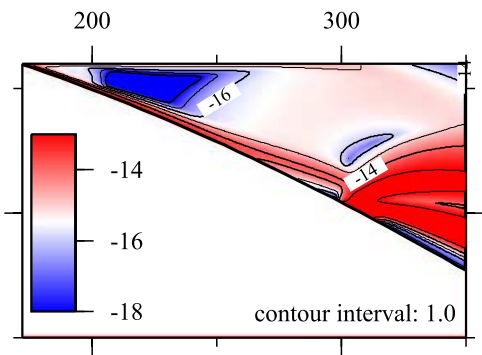

400

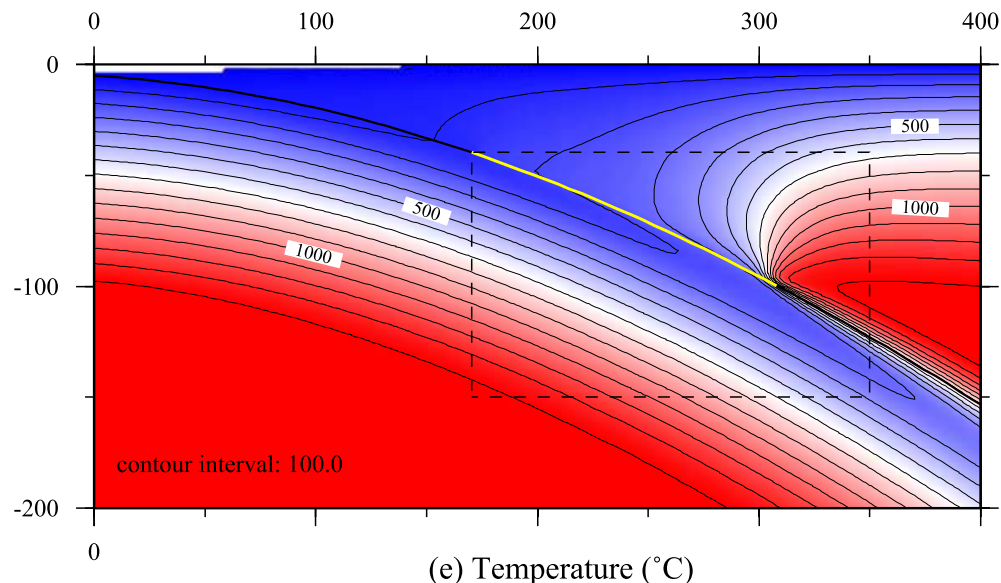

(c) $\log |\mathbf{u}|(\mathrm{cm} / \mathrm{yr})$

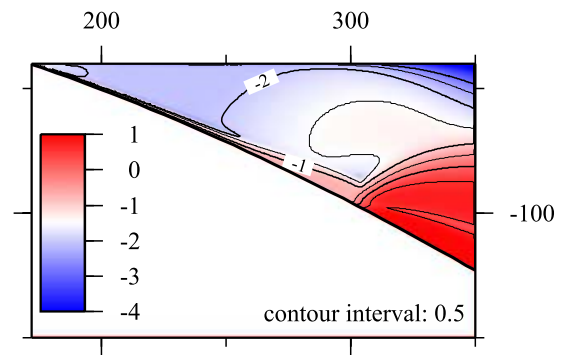

(d) $\log \sigma(\mathrm{MPa})$

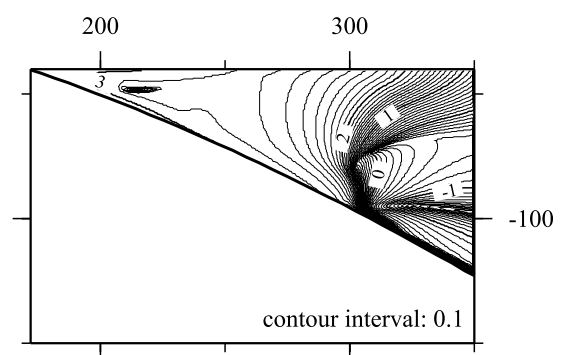

Figure 7. (a) Calculated fabric type, (b) strain rate, (c) magnitude of particle velocity, (d) shear stress, and (e) temperature for a model with $D=100 \mathrm{~km}, \phi=2 \%$, and $S=0 \mathrm{~mW} / \mathrm{m}^{2} / \mathrm{km}$. The zone with reduced velocity boundary condition is denoted with a yellow line.

deformation occurs at a rate of $10^{-14} \mathrm{~s}^{-1}$ (Figure 6b). A very similar pattern of flow and strain rate occurs when $D$ is increased to $100 \mathrm{~km}$ (Figures $7 \mathrm{~b}$ and $7 \mathrm{c}$ ). With this second case, the B-C boundary shifts toward the back arc and the maximum thickness of the B-type region increases to $60 \mathrm{~km}$ (Figures 7a). Figures 7a and 7e show that deep decoupling depresses isotherms which gives rise to a thin layer with Btype conditions at the base of the overriding plate in the back arc (Figures 7a and 7e).

[26] As the magnitude of $\phi$ increases, thermal erosion and the focusing of flow, which are consequences of the temperature dependence of viscosity, increase the amount of advection into the fore-arc mantle. Figure 8 shows a case with $D=100 \mathrm{~km}$ and $\phi=9 \%$. With this case, the hot tongue of corner flow penetrates the fore-arc mantle (Figure 8e) and limits the B-type region to a $20-25 \mathrm{~km}$ thick layer parallel to the surface of the slab (Figure 8a). With larger $\phi$, temperature systematically increases, which causes a reduction of viscous shear stress and a decrease in the volume with conditions suitable for B-type fabric.

[27] When $\phi$ ranges from 1 to $5 \%$, a cold fore-arc mantle develops with B-type conditions, slow flow, and geologically significant deformation. These values of $\phi$ correspond to reduced velocity boundary conditions ranging from approximately 0.1 to $0.45 \mathrm{~cm} / \mathrm{yr}$. With smaller magnitudes of $\phi$, the rate of deformation is too low to produce a seismologically significant fabric. Larger magnitudes of $\phi$ limit B-type fabric to a small region of the fore-arc mantle. Constraints on the maximum possible value of $\phi$ come from the distribution of arc magmatism, heat flow measurements, and seismic attenuation.

[28] We compare measured heat flow from the Honshu subduction system [Furukawa and Uyeda, 1989] to calculated surface heat flow for cases with $D=70 \mathrm{~km}, D=100 \mathrm{~km}$, and a range of $\phi$ (Figures 9a and 9b). We are primarily interested in fore-arc heat flow. Arc heat flow is affected by magma advection, which is not included in the models presented in this study. With both cases (Figures 9a and 9b), calculated heat flow falls within the range of fore-arc observations when $\phi$ is less then $5 \%$. Thus heat flow observations are consistent with a cold slowly flowing fore-arc mantle with thermal and stress conditions suitable for B-type fabric.

[29] When $\phi$ exceeds $10 \%$, temperature in the fore-arc mantle reaches the solidus of water saturated peridotite $\left(1000-1100^{\circ} \mathrm{C}\right)$ [Ulmer, 2001]. The lack of fore-arc magmatism suggests that $\phi$ is lower than this value. Smaller amounts of partial coupling $(\phi<9 \%)$ are also necessary to produce the pattern of attenuation from the tomographic models of Takanami et al. [2000] and Stachnik et al. [2004]. This pattern involves an abrupt transition in attenuation at the interface between the fore-arc and arc mantle.

[30] This first set of models shows that for the assumed olivine rheology, a small amount of viscous coupling between the slab and fore-arc mantle is necessary to 
$D=100 \mathrm{~km} ; \phi=9 \% ; S=0 \mathrm{~mW} / \mathrm{m}^{2} / \mathrm{km}\left(c_{\text {fric }}=0\right)$ (a) Fabric Type

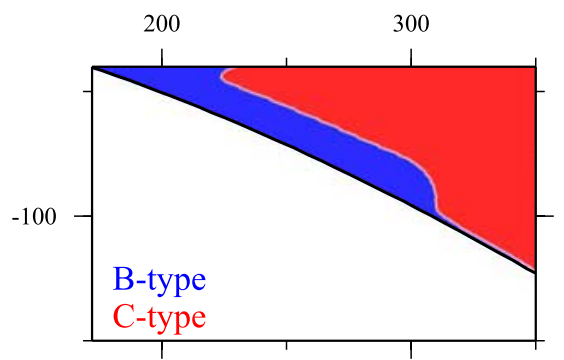

(b) $\log \varepsilon_{\mathrm{T}}\left(\mathrm{s}^{-1}\right)$

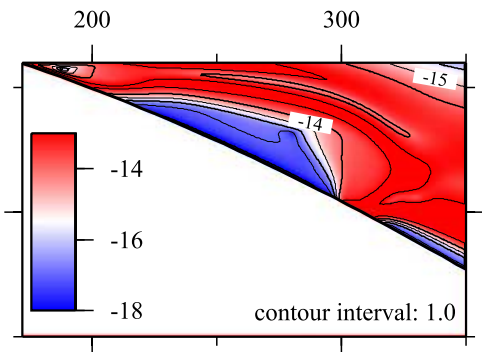

300

200

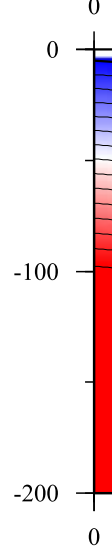

0

100

Distance from Trench $(\mathrm{km})$
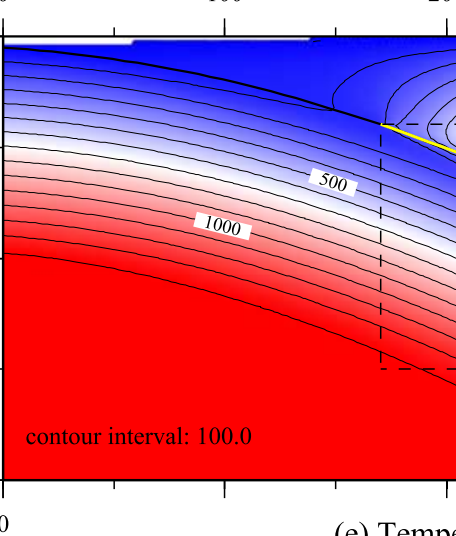

400
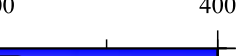
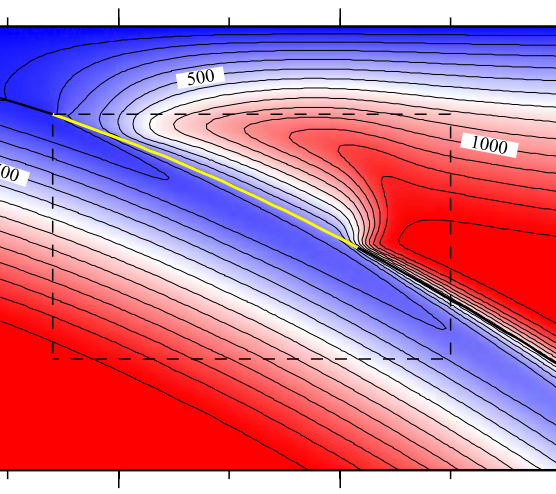

(e) Temperature $\left({ }^{\circ} \mathrm{C}\right)$ (c) $\log |\mathbf{u}|(\mathrm{cm} / \mathrm{yr})$

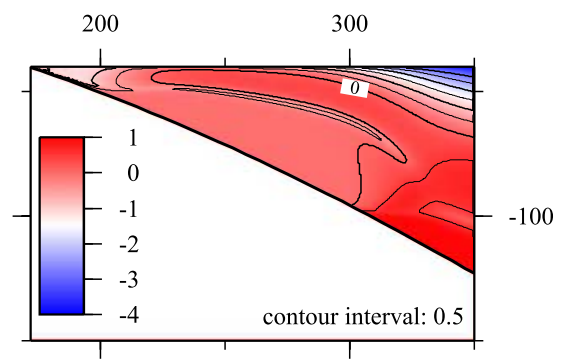

(d) $\log \sigma(\mathrm{MPa})$

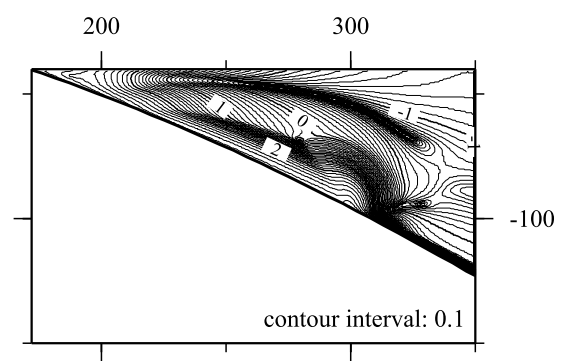

Figure 8. (a) Calculated fabric type, (b) strain rate, (c) magnitude of particle velocity, (d) shear stress, and (e) temperature for a model with $D=100 \mathrm{~km}, \phi=9 \%$, and $S=0 \mathrm{~mW} / \mathrm{m}^{2} / \mathrm{km}$. The zone with reduced velocity boundary condition is denoted with a yellow line.

produce steady-state thermal structures that show reasonable agreement with heat flow data, the distribution of arc magmatism, and seismic attenuation. A small amount of viscous coupling is also necessary to produce large volumes of peridotite in the fore-arc mantle with thermal and stress conditions suitable for B-type fabric.

[31] The previous models included viscous dissipation in the deforming wedge. The magnitude of viscous dissipation ranges from $1 \mu \mathrm{W} / \mathrm{m}^{3}$ in the shear zone next to the slab to $0.1 \mu \mathrm{W} / \mathrm{m}^{3}$ in the core of the cold fore-arc mantle. Viscous dissipation is low $\left(<10^{-2} \mu \mathrm{W} / \mathrm{m}^{3}\right)$ in the core of the hot wedge and has a negligible effect on thermal structure. The additions of viscous dissipation causes an increases in temperature of around $100-150^{\circ} \mathrm{C}$ in the core of the forearc mantle, which produces a decrease in viscous shear stress of around $100 \mathrm{MPa}$.

[32] As described in section 3.1, we cannot model shear heating associated with fault slip in a completely selfconsistent manner. However, the importance of shear heating can be investigated by adding a heat production term (see section 3.1). Figure 10 shows a case with $D=100 \mathrm{~km}$, $\phi=2 \%$, and $S=5 \mathrm{~mW} / \mathrm{m}^{2} / \mathrm{km}\left(c_{\text {fric }}=0.053\right)$. The addition of shear heating does not significantly affect the distribution of fabric type (Figure 10a) but does causes a localization of deformation closer to the B-C boundary (Figure 10b). Furthermore, the addition of shear heating significantly reduces the shear stress necessary to drive significant deformation in the B-type region to values that range from less than 100 to $300 \mathrm{MPa}$ (Figure 10d). This is a significant decrease from the shear stress associated with the previous cases (600-800 MPa) (Figures 6d, 7d, and 8d). Shear heating gradients ranging from 3 to $5 \mathrm{~mW} / \mathrm{m}^{2} / \mathrm{km}$ produce a magnitude of heat flow that falls within the scatter of observations from the fore arc (Figure 9c).

[33] It is important to note that P-T conditions in our models are inconsistent with geothermometry and barometry based on mantle-melt equilibrium [Kelemen et al., 2003], which suggests temperatures as high as $1300^{\circ} \mathrm{C}$ at the base of the arc crust. This discrepancy may be due to the lack of magma transport in our models. Buoyancy driven advection could also locally elevate isotherms beneath arcs and may be associated with small-scale convection induced by hydrogen point defects or melt [Arcay et al., 2005]. These local advective processes would have only a limited effect on fore-arc thermal structure and be consistent with the abrupt spike in heat flow observed at the volcanic front of subduction zones [Furukawa and Uyeda, 1989; Currie et al., 2004] (Figure 9).

[34] P-T estimates based on mantle-melt equilibrium [Kelemen et al., 2003] may only provide constraints on local conditions beneath volcanic centers. Volcanism is not a continuous phenomena and thus such estimates may not apply to the entire mantle wedge. For example, the tomographic models of Japan suggest that volcanic centers are associated with buoyant tongues of locally hot mantle 

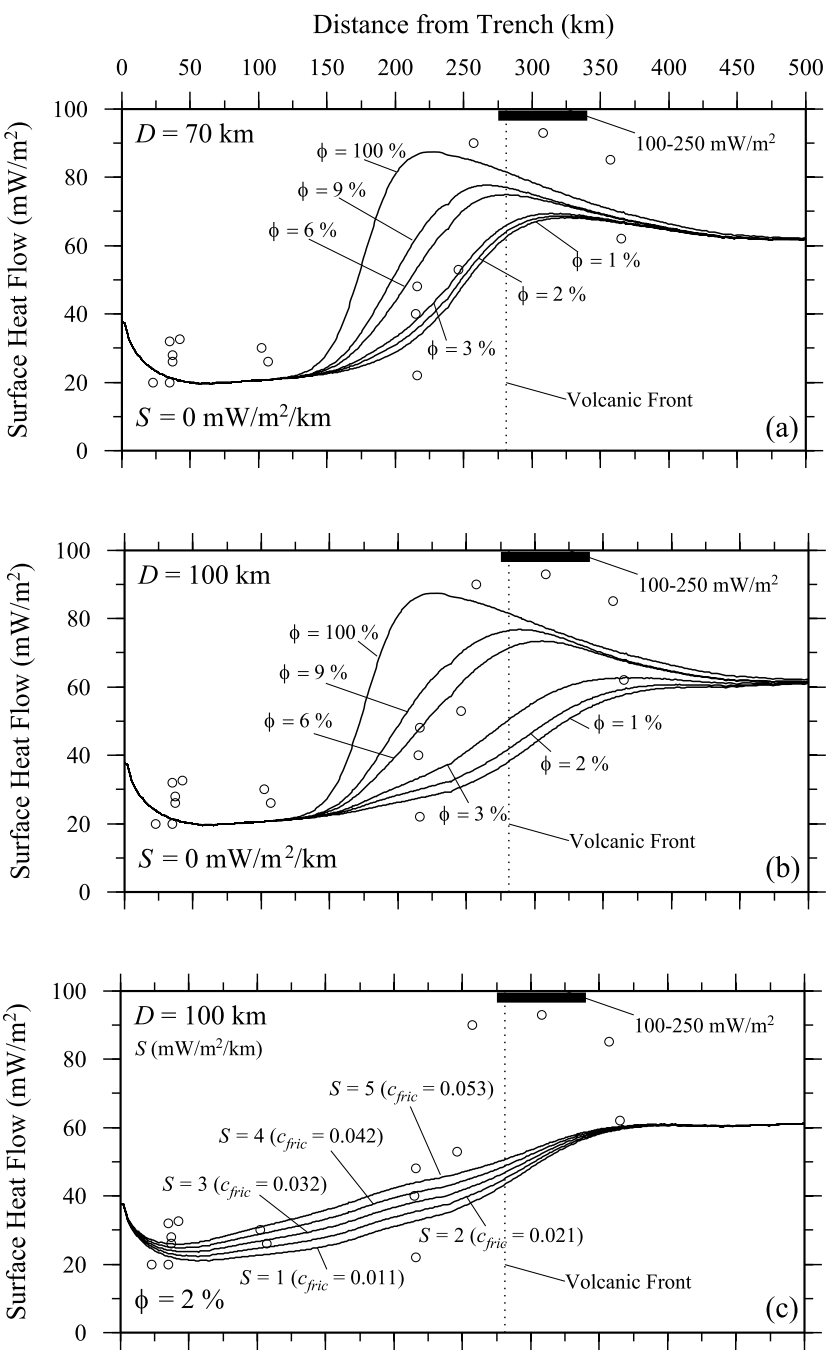

Figure 9. ( $a$ and b) Calculated heat flow for variable viscous coupling and (c) variable shear heating gradient. Figure 9a shows results for models with $D=70 \mathrm{~km}$. Figures $9 \mathrm{~b}$ and $9 \mathrm{c}$ show results for models with $D=100 \mathrm{~km}$. Heat flow observations are from the Honshu subduction system [Furukawa and Uyeda, 1989].

[Tamura et al., 2002]. We also note that the Ryukyu subduction system, where widespread trench-parallel shear wave splitting has been observed [Long and van der Hilst, 2005], has large gaps in active volcanism suggesting that temperatures may be relatively low in parts of the mantle wedge.

\subsection{Finite Strain Calculations}

[35] Finite strain is calculated only in particles within the region where thermal and stress conditions are suitable for B-type fabric. This region is confined to the fore-arc mantle where particle velocity is one to two orders of magnitude lower than particle velocity in the rapidly convecting core of the wedge (Figures $6 \mathrm{c}, 7 \mathrm{c}, 8 \mathrm{c}$, and 10c). Here we show finite strain accumulation in the B-type region for cases with variable partial coupling and shear heating (Figures 11-14).

[36] For the first case $(\phi=1 \%$, Figure 11), sufficient finite strain $(\zeta=0.3)$ develops in the core of the fore-arc mantle after 150 Myr. The period of time necessary to develop sufficient strain in the B-type region is reduced to around $13 \mathrm{Myr}$ with $\phi=3 \%$ (Figure 13). Cases 1 to 3 (Figures $11-13$ ) show results for a range of $\phi$ that produces ideal conditions for B-type fabric development. The volume of B-type conditions systematically decreases with larger values of $\phi$. When $\phi$ is below $1 \%$, sufficient strain accumulation requires a duration of time that exceeds the age of the Honshu subduction system (150 Myr) [Jarrard, 1986]. With cases 1 to 3, particles slowly flow into the B-type region and accumulate a magnitude of finite strain greater than 0.3 over a distance ranging from 10 to $20 \mathrm{~km}$.

[37] The addition of shear heating localizes strain closer to the B-C boundary and reduces the total volume of material in the fore-arc mantle with B-type conditions and sufficient finite strain accumulation (Figure 14). However, the local increase in strain rate associated with shear heating reduces the time required to generate sufficient strain in the core of the fore-arc (compare Figures 12 and 14).

\section{Fore-Arc Serpentinization}

[38] Temperatures are below the antigorite stability temperature $\left(650-700^{\circ} \mathrm{C}\right)$ [Ulmer and Trommsdorff, 1995; Bromiley and Pawley, 2003; Komabayashi et al., 2005] throughout large regions of the fore-arc mantle for several models presented in this work. This may imply that olivine deformation is inhibited in these parts of the fore-arc mantle and the lack of B-type fabric. However, other requirements must be met in order to extensively serpentinized peridotite in the fore-arc mantle: (1) significant amounts of chemically bound water must be released from the subducting slab (serpentine has $13 \mathrm{wt}_{0} \mathrm{H}_{2} \mathrm{O}$ ), and (2) water must be transported throughout the fore-arc mantle. Estimates of the amount of water released by the slab indeed suggest that enough water may be released by the slab to completely serpentinize the cold nose in less than $10 \mathrm{Ma}$ [Schmidt and Poli, 1998; Hyndman and Peacock, 2003]. However, the mechanism of transport in the fore-arc mantle is poorly understood [Hyndman and Peacock, 2003]. Water may only work its way into the wedge via fractures, which would produce heterogeneous serpentinization [Hyndman and Peacock, 2003]. It is also possible that serpentinization occurs in a relatively thin layer above the slab, the effects of which are simulated in our models with a reduced boundary condition. Moreover, extensive serpentinization in the fore-arc mantle may be dynamically unstable due to the associated reduction in density and strength. If serpentinization is only a local phenomenon concentrated along fractures, then it may not have a significant effect on bulk rheology. This will strongly depend on the interconnection of serpentine veins in the fore-arc mantle, which is unknown.

[39] Hyndman and Peacock [2003] argued for extensive fore-arc serpentinization based on the relatively low seismic velocity and high Poisson ratio observed in the fore-arc mantle of several subduction zones. However, Christensen [2004] suggests that these observations could also be caused by seismic anisotropy associated with deformed olivine aggregates or the presence of chlorite. Furthermore, seismic evidence for serpentinization is not observed in all subduction zones. For example, tomographic studies from New Zealand [Reyners et al., 2006] and Japan [Zhang et al., 2004] 
$D=100 \mathrm{~km} ; \phi=2 \% ; S=5 \mathrm{~mW} / \mathrm{m}^{2} / \mathrm{km}\left(c_{\text {fric }}=0.053\right)$

(a) Fabric Type

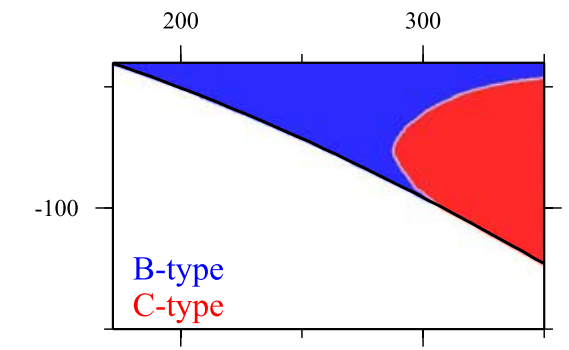

(b) $\log \varepsilon_{\mathrm{T}}\left(\mathrm{s}^{-1}\right)$

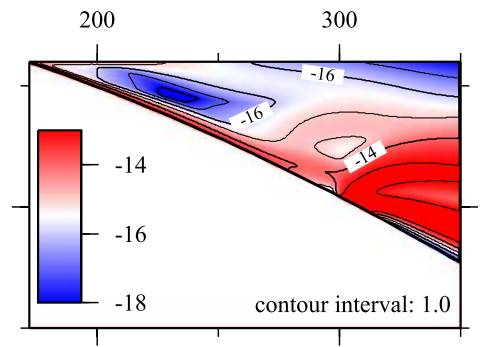

Distance from Trench $(\mathrm{km})$

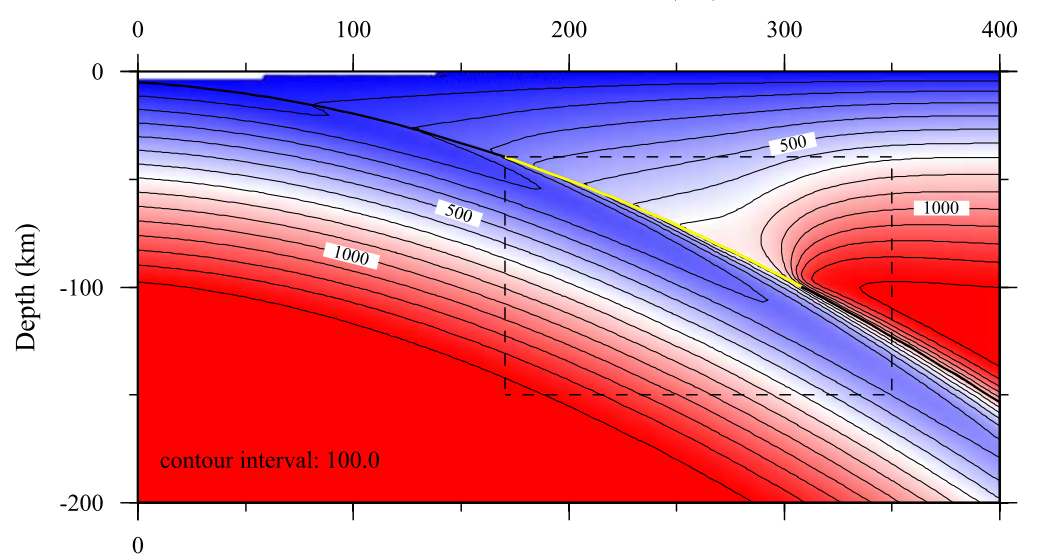

400

(e) Temperature $\left({ }^{\circ} \mathrm{C}\right)$ (c) $\log |\mathbf{u}|(\mathrm{cm} / \mathrm{yr})$

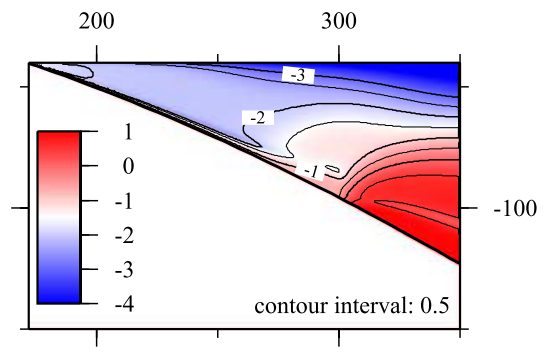

(d) $\log \sigma(\mathrm{MPa})$

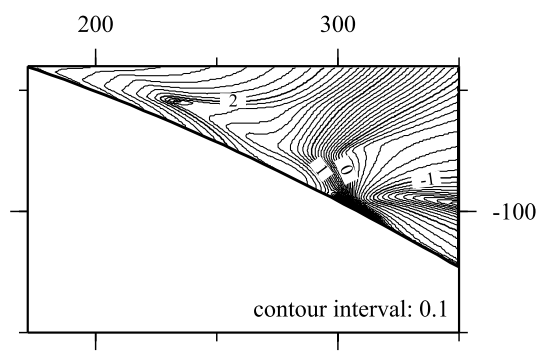

Figure 10. (a) Calculated fabric type, (b) strain rate, (c) magnitude of particle velocity, (d) shear stress, and (e) temperature for a model with $D=100 \mathrm{~km}, \phi=2 \%$, and $S=5 \mathrm{~mW} / \mathrm{m}^{2} / \mathrm{km}$. The zone with reduced velocity boundary condition is denoted with a yellow line.

show $\mathrm{V}_{p} / \mathrm{V}_{s}$ ratios that are not consistent with extensive serpentinization in the fore arc. Seismic evidence for serpentine also tends to suggest serpentinization at depths less than $50 \mathrm{~km}$, which is much shallower than where our calculations predict B-type fabric [Suyehiro et al., 1996; Fliedner and Klemperer, 1999; Kamiya and Kobayashi, 2000]. Direct evidence for subcrustal serpentinization comes from serpentine mud volcanoes and diapirs observed throughout the fore arc of the Izu-Bonin-Marianas system. These features occur at very shallow depth $(10 \mathrm{~km})$ and provide little information about serpentinization in the deep fore-arc mantle [Suyehiro et al., 1996]. Magnetotelluric studies have also been used to probe the fore-arc mantle for serpentine but the results are inconclusive [Soyer and Unsworth, 2006].

[40] In this paper we take an important first step by incorporating the most up to date experimentally based wet olivine rheology that includes low-temperature exponential creep and experimental constraints on the B-C olivine fabric transition. By "wet" we are not referring to free water released by the slab but to hydrogen point defects within olivine that may be present in the mantle before subduction initiates [Hirth and Kohlstedt, 1996]. We argue that this is a reasonable end-member model given the uncertainty associated with fore-arc serpentinization. It is also important to note that our most realistic models, which have reasonable stresses and include shear heating, show a very large region with B-type conditions that is outside of the antigorite stability field. When the uncertainty of the B$\mathrm{C}$ transition at $10 \mathrm{MPa}$ stress is taken into account (700$900^{\circ} \mathrm{C}$ ) the B-type region outside of the Antigorite stability field could be $30 \mathrm{~km}$ wider than predicted by or models.

[41] Serpentine may play an important role in fore-arc dynamics. For example, if pervasive serpentinization gives rise to sufficient weakening and strain localization in the slab-wedge interface then deformation in the core of the fore-arc mantle may be inhibited. However, the extent and distribution of serpentinite are poorly constrained. The lack of experimental data on the high-pressure ductile rheology of serpentinite and variably serpentinized peridotite makes investigating the role of serpentinite even more difficult. For example, we are aware of only one published stress-strainrate data point for ductile deformation of $90 \%$ serpentinized peridotite [Rayleigh and Paterson, 1965]. More experimental work is necessary in order to provide better constraints on geodynamic models. We present a possible end-member model where deformation in the fore-arc mantle is governed by an olivine rheology and leave the testing of the serpentinite end-member model for future studies that may have better available constraints.

\section{Discussion and Conclusions}

[42] The sensitivity tests presented in this work show that with the assumed olivine rheology, a small amount of viscous coupling produces a reasonable match with heat 


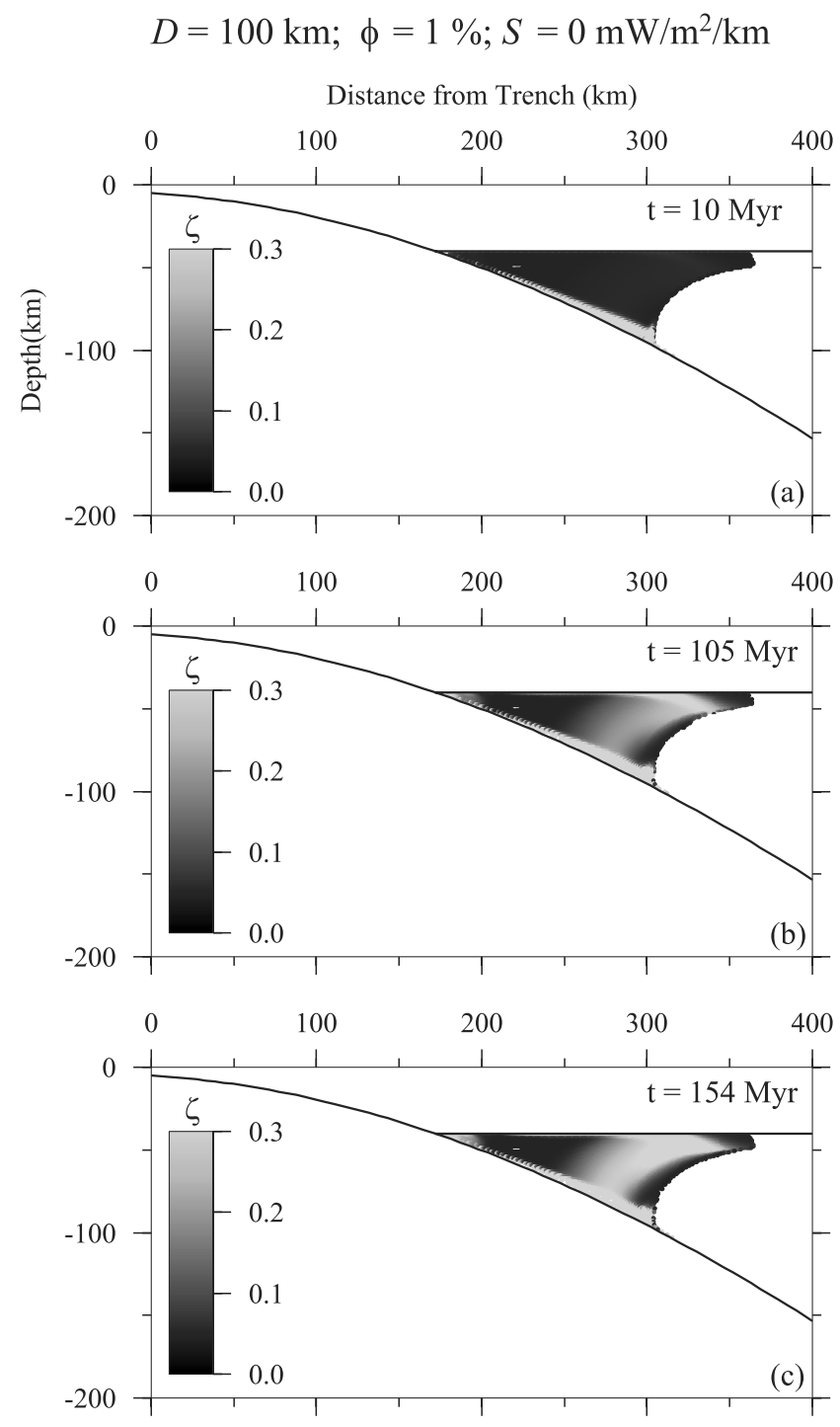

Figure 11. Finite strain accumulation in the predicted B-type region for a case with $D=100 \mathrm{~km}, \phi=1 \%$, and $S=$ $0 \mathrm{~mW} / \mathrm{m}^{2} / \mathrm{km}$. The grayscale denotes $\zeta$ ranging from 0 (black) to greater than or equal to 0.3 (gray). A value of $\zeta$ equal to or greater than 0.3 is required to generate a seismologically significant fabric. Particles outside of the B-type region are not shown. Particles are plotted as circles with a radius equal to $2.5 \mathrm{~km}$.

flow, Q tomography, and the distribution of arc volcanism. B-type fabric is stable in the fore-arc mantle when viscous flow is a small percentage of the total deformation (i.e., $\phi<$ $5 \%$ ) at the slab-wedge interface. The distance over which Btype conditions extend into the back arc is controlled by the depth at which the slab and mantle wedge become fully coupled (i.e., $D$ ) and the amount of viscous coupling $\phi$. For cases with $D$ set to the maximum possible depth and moderate amounts of viscous coupling (e.g., Figure 7), a layer of B-type fabric is observed at the base of overriding plate in the arc mantle (Figures 11-13). Our models do not include the addition of heat to this region via magma advection, which would probably produce temperatures that are too high for B-type fabric. Our models predict that the volcanic arc will approximately mark the maximum possible lateral extension of B-type fabric. Sufficient finite strain is predicted to accumulate in the core of the fore-arc mantle. The timescale of significant B-type fabric development ranges from 10 to $150 \mathrm{Myr}$ depending on the magnitude of the velocity boundary condition along the aseismic creeping zone and the amount of shear heating. These timescales fall within the age of many subduction systems [Jarrard, 1986]. A summary of the main conclusions obtained from the calculations presented in this work is shown in Figure 15.

[43] The shear stress necessary to generate a large region with B-type conditions at geologically significant strain rates has important implications for the B-type fabric hypothesis. This required shear stress can be used to test the validity of the B-type hypothesis by considering the strength of olivine aggregates, observational constraints on deviatoric stress, and slab dynamics.

[44] The maximum strength of olivine aggregates is limited by frictional failure strength at shallow depths and

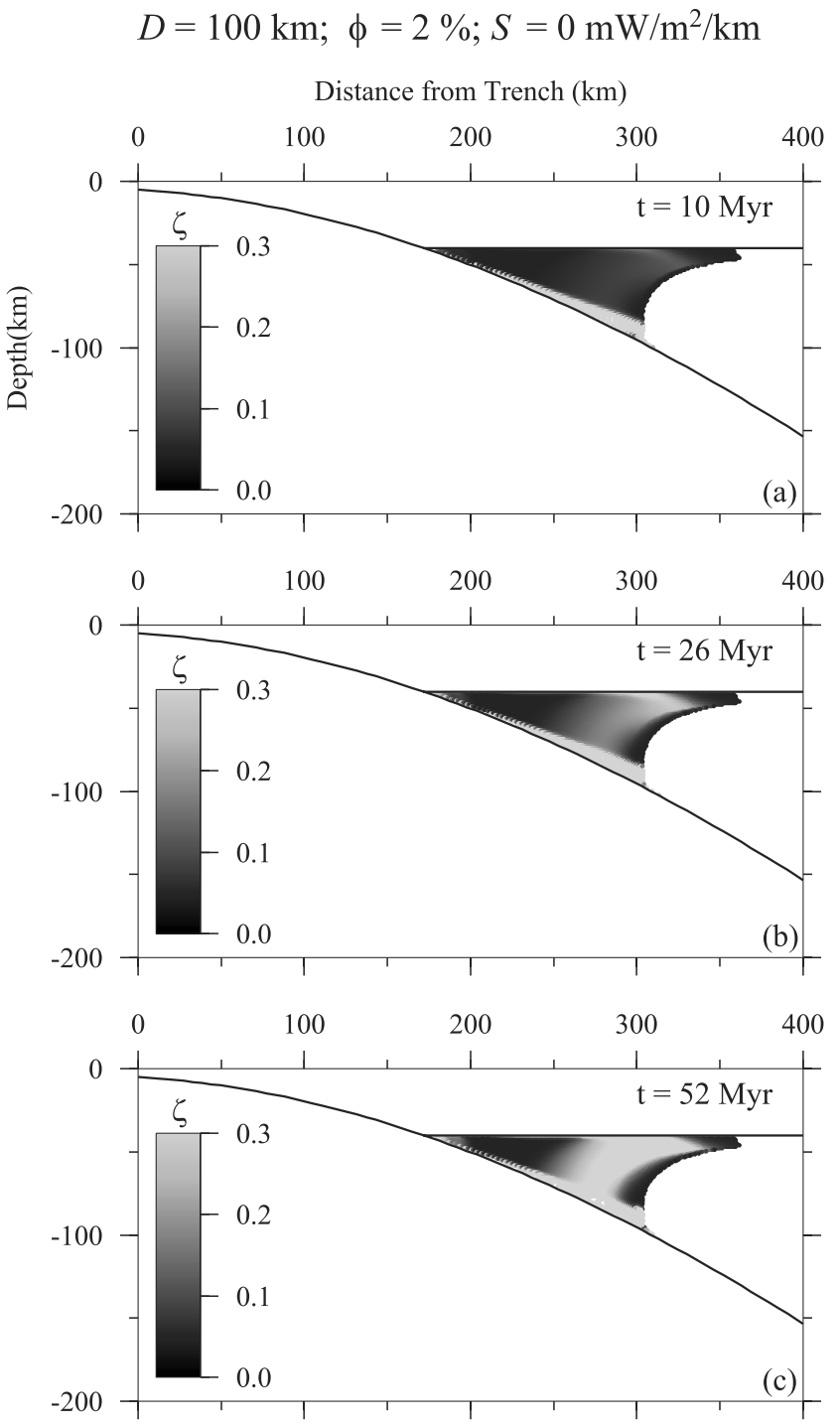

Figure 12. As in Figure 10, but now with $\phi=2 \%$. 

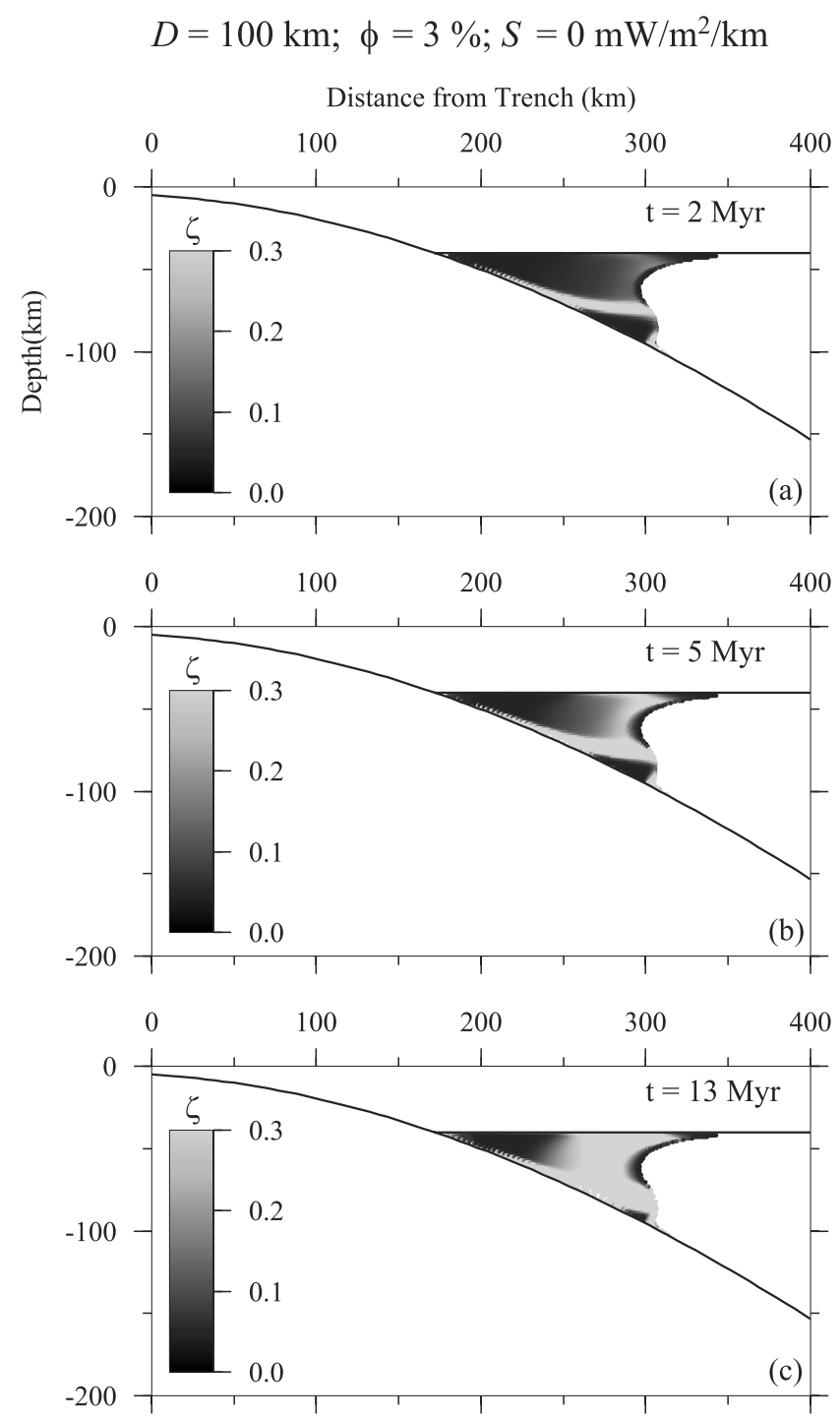

Figure 13. As in Figure 10, but now with $\phi=3 \%$.

fracture strength at depths greater than $10 \mathrm{~km}$. Using these deformation processes as limits, the maximum sustainable shear stress in the fore-arc mantle is around $600 \mathrm{MPa}$ [Kohlstedt et al., 1995]. Observational constraints come from coseismic stress drop (0.1-30 MPa) [Scholz, 2002] and grain size piezometry $(10-400 \mathrm{MPa})$ [Twiss, 1977]. Coseismic stress drop provides a lower limit on the magnitude of deviatoric stress and is limited to seismogenic regions.

[45] Slab force balance provides constraints on the upper limit of viscous resistance. The total body force acting on a typical slab subducting through the transition zone is approximately $5 \times 10^{13} \mathrm{~N} / \mathrm{m}$ [Turcotte and Schubert, 2002]. Shear resistance along a $100 \mathrm{~km}$ aseismic creep zone with $500 \mathrm{MPa}$ of resistive viscous stress produces a resistive force equal to $5 \times 10^{13} \mathrm{~N} / \mathrm{m}$, a magnitude of force almost large enough to cause the cessation of subduction. Therefore viscous resistance acting on the subducting slab along the aseismic creep zone must be less than around $500 \mathrm{MPa}$.

[46] For the rheological model of Katayama and Karato (submitted manuscript, 2007) and without shear heating, the deviatoric stress necessary to generate viscous flow in the cold fore-arc mantle ranges from 300 to $600 \mathrm{MPa}$ in the core of the fore-arc mantle to $900 \mathrm{MPa}$ close to the slab (Figures 6d and 7d). Shear stress ranging from 600$900 \mathrm{MPa}$ is beyond the upper limits of observational constraints, is greater than the strength of the material, and gives rise to problems with slab dynamics as discussed above. With $S$ between 3 and $5 \mathrm{~mW} / \mathrm{m}^{2} / \mathrm{km}$ most of the fore-arc mantle has B-type conditions and required shear stress ranges from 100 to $300 \mathrm{MPa}$ for the experimentally based low-temperature parameters (e.g., Figure 10d). These shear stresses are below the upper limits set by slab dynamics and are within the range of uncertainty associated with observational constraints.

[47] Lassak et al. [2006] implement a more complicated description of fabric development, which includes intracrystalline slip and dynamic recrystallization, but with significantly more simplified rheological description. These models predict that a larger B-type region extending into the arc and back arc and $\zeta$ equal to 0.6 may be necessary to generate B-type fabric close to the trench. This is largely due the open nature of the fore-arc mantle in isoviscous

$$
D=100 \mathrm{~km} ; \phi=2 \% ; S=5 \mathrm{~mW} / \mathrm{m}^{2} / \mathrm{km}
$$

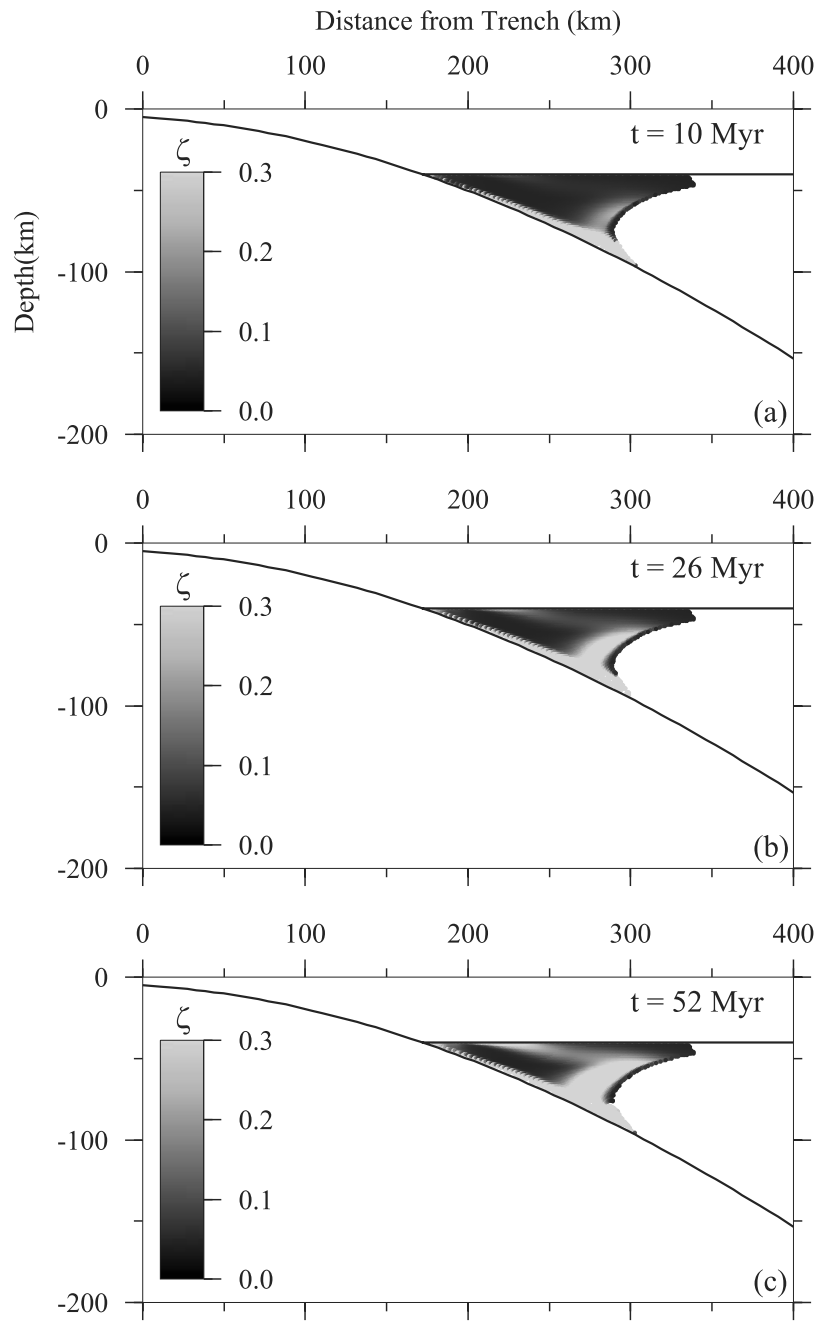

Figure 14. As in Figure 10, but now with $\phi=2 \%$, and $S=$ $5 \mathrm{~mW} / \mathrm{m}^{2} / \mathrm{km}$. 


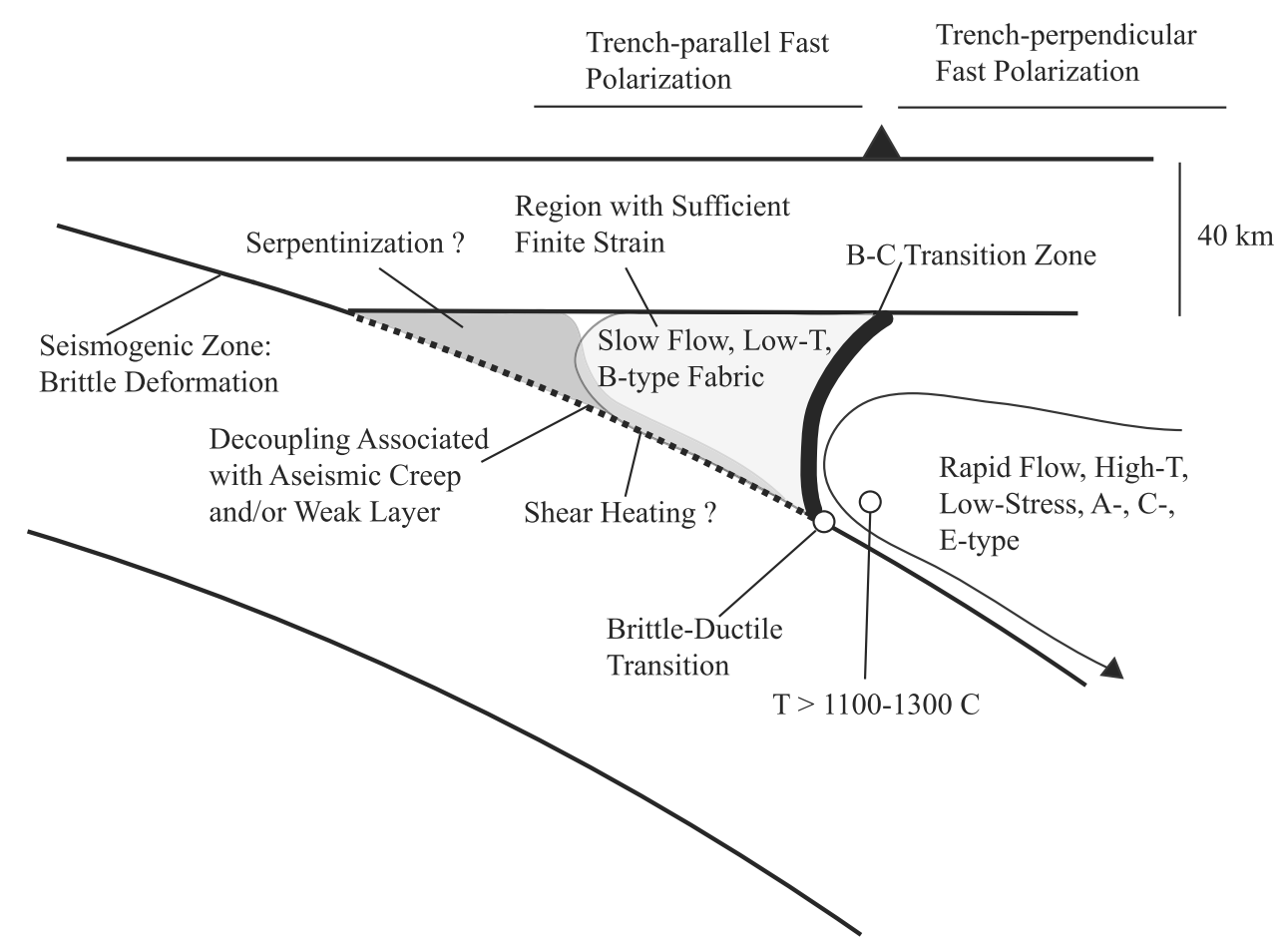

Figure 15. Summary of model results. The best candidate region of the mantle wedge for B-type conditions with sufficient finite strain accumulation is in the central region of the fore-arc mantle (denoted by gray shading). The formation of this B-type region requires partial coupling between the slab and mantle wedge (denoted by a dashed line), which produces a fore-arc mantle with slow flow and heat transport dominated by conduction. Particles that slowly travel into the B-type region accumulate finite strain $(\zeta)$ greater than 0.3 in a narrow zone. Shear heating in the partially coupled zone is necessary to generate geologically significant deformation at realistic deviatoric stress. The depth of the transition from partial to full viscous coupling (brittle-ductile transition) controls the maximum lateral extend of the B-type fabric into the back arc. Our models predict that the volcanic arc will mark an abrupt transition from B-type fabric in the cold nose of the mantle wedge to C-type or other fabrics in the hot core of the wedge. The predicted pattern of shear-wave splitting consists of trench-parallel fast polarization in the fore-arc and trench-perpendicular in the back arc (see Figure 1). The presence of serpentine may play an important role in controlling fabric development in the colder regions of the fore-arc mantle.

models which requires the destruction of a strong preexisting fabric during fabric development in the B-type region. Our models show that B-type conditions occur in the forearc mantle when flow is slow and relatively isolated from the wedge core (e.g., Figures $6 \mathrm{c}$ and $7 \mathrm{c}$ ). With this scenario, a strong preexisting fabric does not necessarily have to be destroyed and B-type fabric development may require a smaller amount of strain.

[48] The pattern of shear-wave splitting predicted by Kneller et al. [2005] is supported by the improved models presented in this paper (Figures 1 and 15). This pattern involves trench-parallel fast directions close to the trench, a rotation across the volcanic front to trench-perpendicular fast directions in the back-arc mantle, and a maximum trenchparallel splitting time of $1 \mathrm{~s}$ (Figure 1). This predicted pattern of anisotropy adequately explains shear-wave splitting observations from Honshu [Nakajima and Hasegawa, 2004], Southern Japan [Long and van der Hilst, 2005], Ryukyu [Long and van der Hilst, 2005], and Southern Kurile [Nakajima et al., 2006] subduction systems. The age of these subduction systems ranges from 50 to 160 Myr [Jarrard, 1986]. This range is within the range of time necessary for significant B-type fabric development (10-150 Myr). Trench-parallel anisotropy from parts of the Andean [Anderson et al., 2004] subduction system may also be explained by the B-type fabric anisotropy hypothesis.

[49] Several subduction systems show patterns of anisotropy that are not predicted by our models. These include: (1) Tonga [Smith et al., 2001] and parts of the Andean system [Anderson et al., 2004] with trench-parallel anisotropy extending far into the back-arc mantle, (2) Cascadia [Currie et al., 2001, 2004] where fast directions appear to be dominantly trench-perpendicular in the fore-arc and arc mantle, (3) Kamchatka [Levin et al., 2004] with complex patterns of shear-wave splitting, and (4) Alaska [Christensen et al., 2003] where the pattern of shear-wave splitting is opposite from that predicted with 2-D flow and B-type fabric. This diversity of patterns of seismic anisotropy suggests that a variety of processes may play important roles. It is possible that serpentinization, 3-D flow processes, fabric within the slab, and/or melt networks [Holtzman et al., 2003] are affecting anisotropy in some subduction systems. Geodynamic modeling has yet to thoroughly investigate the dynamics of serpentinization in the fore-arc 
mantle and the influence of variable slab geometry and olivine rheology on fabric development in 3-D subduction zone models. These are subjects of future research.

\section{Appendix A}

[50] Here we describe the algorithm used to obtain steady-state numerical solutions to equations (2)-(4). This algorithm deals with the nonlinear exponential nature of the rheology and the addition of viscous dissipation to the heat equation. The quantities approximated via the solution of equations (2)-(4) are velocity $\mathbf{u}$, temperature $T$, and pressure $P$. The second invariant of the strain rate tensor $\dot{\epsilon}$, which is calculated with derivatives of the velocity field, viscosity $\eta$, viscous dissipation $q_{\text {dissi }}$, and shear stress $\sigma$ are quantities used in the description of the algorithm. The algorithm is summarized as follows:

\section{Spin up}

1: $\mathbf{u}_{\text {new }}$ is obtained by solving equation (2) with isoviscous rheology

2: equation (4) is solved with $\mathbf{u}_{n e w}$ and without the viscous dissipation term to obtain $T_{\text {new }}$

3: $\eta$ is defined by equation (17) and $\mathbf{u}_{\text {new }}$ is obtained by solving equation (2); $\dot{\varepsilon}$ is calculated

Main Loop: until convergence is reached (convergence criterion $10^{-5}$ )

4: $T_{\text {old }}$ is set equal to $T_{\text {new }}$

Subloop: until convergence is reached (convergence criterion $10^{-3}$ )

5: $\mathbf{u}_{\text {old }}$ is set equal to $\mathbf{u}_{\text {new }}$

6: $\sigma$ and $\eta$ are obtained by solving equation (6) using $\dot{\epsilon}$

and equation (21)

7: $\mathbf{u}_{\text {new }}$ is obtained by solving equation (2) with $\eta$

\section{End Subloop}

8: $q_{\text {dissi }}$ is calculated with equation (5) using $\sigma$ and $\dot{\epsilon}$

9: equation (4) is solved using $\mathbf{u}_{n e w}$ and $q_{d i s s i}$

10: relaxation is applied; $T_{\text {new }}=0.5\left(T_{\text {new }}+T_{\text {old }}\right)$ and $\mathbf{u}_{\text {new }}=$

$0.5\left(\mathbf{u}_{\text {new }}+\mathbf{u}_{\text {old }}\right)$

End Main Loop

[51] Acknowledgments. We thank Larry Ruff, Greg Hirth, Brad Hacker, Geoff Abers, Jeffrey Park, and Maureen Long for thoughtful comments and stimulating discussions. This research is supported by the National Science Foundation (EAR-0208310).

\section{References}

Anderson, M. L., G. Zandt, E. Triep, M. Fouch, and S. Beck (2004), Anisotropy and mantle flow in the Chile-Argentina subduction zone from shear wave splitting analysis, Geophys. Res. Lett., 31, L23608, doi:10.1029/2004GL020906.

Arcay, D., E. Tric, and M. Doin (2005), Numerical simulations of subduction zones: Effect of slab dehydration on the mantle wedge dynamics, Phys. Earth Planet. Int., 149, 133-153.

Billen, M. I., and M. Gurnis (2001), A low viscosity wedge in subduction zones, Earth Planet. Sci. Lett., 193, 227-236.

Bromiley, G., and A. Pawley (2003), The stability of antigorite in the systems $\mathrm{MgO}-\mathrm{SiO}_{2}-\mathrm{H}_{2} \mathrm{O}(\mathrm{MSH})$ and $\mathrm{MgO}-\mathrm{Al}_{2} \mathrm{O}_{3}-\mathrm{SiO}_{2}-\mathrm{H}_{2} \mathrm{O}$ (MASH): The effects of $\mathrm{Al}^{3+}$ substitution on high-pressure stability, Am. Mineral., $88,99-1082$

Christensen, D. H., G. A. Abers, and T. McNight (2003), Mantle anisotropy beneath the Alaska range inferred from s-wave splitting observations: results from BEAAR, Eos Trans. AGU, 84, Fall Meet. Suppl., Abstract S31C-96-0782.

Christensen, N. I. (2004), Serpentinites, peridotites, and seismology, Int Geol. Rev., 46, 795-816.

Conder, J. A. (2005), A case for hot slab surface temperatures in numerical viscous flow models of subduction zones with improved fault zone parameterization, Earth Planet. Sci. Lett., 149, 155-164.
Cordellier, F., F. Boudier, and A. M. Boullier (1981), Structural study of the Almklovdalen peridotite massif (southern Norway), Tectonophysics, 77 $257-281$.

Currie, C. A., J. F. Cassidy, and R. D. Hyndman (2001), A regional study of shear wave splitting above the Cascadia subduction zone: Margin-parallel crustal stress, Geophys. Res. Lett., 28, 659-662.

Currie, C. A., J. F. Cassidy, R. D. Hyndman, and M. G. Bostock (2004), Shear wave anisotropy beneath the Cascadia subduction zone and western North American craton, Geophys. J. Int., 157, 341-353.

Cuvelier, C., A. Segal, and A. A. van Steenhoven (1986), Finite Element Methods and Navier-Stokes Equations, 483 pp., Springer, New York.

Davies, J. H., and D. J. Stevenson (1992), Physical model of source region of subduction zone volcanics, J. Geophys. Res., 97, 2037-2070.

England, P., R. Engdahl, and W. Thatcher (2004), Systematic variation in the depths of slabs beneath arc volcanoes, Geophys. J. Int., 156, $377-$ 408 .

Fliedner, M., and S. Klemperer (1999), Structure of an island-arc: Wideangle seismic studies in the eastern Aleutian Islands, Alaska, J. Geophys. Res., 104, 10,667-10,694.

Frese, K., V. Trommsdorff, and K. Kunze (2003), Olivine [100] normal to foliation: lattice preferred orientation in prograde garnet peridotite formed at high $\mathrm{H}_{2} \mathrm{O}$ activity, Cima di Gagnone (Central Alps), Contrib. Mineral. Petrol., 145, 75-86.

Furukawa, Y. (1993), Depth of the decoupling plate interface and thermal structure under arcs, J. Geophys. Res., 98, 20,005-20,013.

Furukawa, Y., and S. Uyeda (1989), Thermal structure under the Tohoko arc with consideration of crustal heat generation, Tectonophysics, 164 $175-187$.

Hirth, G., and D. L. Kohlstedt (1996), Water in the oceanic upper mantle: Implications for rheology, melt extraction and the evolution of the lithosphere, Earth Planet. Sci. Lett., 144, 93-108.

Holtzman, B. K., D. L. Kohlstedt, M. E. Zimmerman, F. Heidelback, T. Hiraga, and J. Hustoft (2003), Melt segregation and strain partitioning: Implications for seismic anisotropy and mantle flow, Science, 301, $1227-1230$

Hyndman, R. D., and S. M. Peacock (2003), Serpentinization of the fore arc mantle, Earth Planet. Sci. Lett., 212, 417-432.

Jarrard, R. D. (1986), Relations among subduction parameters, Rev. Geophys., 24, 217-284.

Jung, H., and S. Karato (2001), Water-induced fabric transition in olivine, Science, 293, 1460-1463.

Kamiya, S., and Y. Kobayashi (2000), Seismological evidence for the existence of serpentinized wedge mantle, Geophys. Res. Lett., 27, 819-822.

Karato, S. (2003), Mapping water content in the upper mantle, in Inside the Subduction Factory, Geophys. Monogr. Ser., vol. 138, edited by J. Eiler, pp. 135-149, AGU, Washington, D. C.

Karato, S., and H. Jung (2003), Effects of pressure on high-temperature dislocation creep in olivine, Philos. Mag., 83, 401-414.

Katayama, I., and S. Karato (2006), Effect of temperature on the B- to C-type olivine fabric transition and implication for flow pattern in subduction zones, Phys. Earth Planet. Int., 157, 33-45.

Katayama, I., H. Jung, and S. Karato (2004), New type of olivine fabric from deformation experiments at modest water content and low stress, Geology, 32, 1045-1048.

Katayama, I., S. Karato, and M. Brandon (2005), Evidence of high water content in the deep upper mantle inferred from deformation microstructures, Geology, 33, 613-616.

Kelemen, P. B., J. L. Rilling, E. M. Parmentier, L. Mehl, and B. R. Hacker (2003), Thermal structure due to solid-state flow in the mantle wedge beneath arcs, in Inside the Subduction Factory, Geophys. Monogr. Ser. vol. 138, edited by J. Eiler, pp. 293-311, AGU, Washington, D. C.

Kneller, E. A., P. E. van Keken, S. Karato, and J. Park (2005), B-type olivine fabric in the mantle wedge: Insights from high-resolution nonNewtonian subduction zone models, Earth Planet. Sci. Lett., 237, 781797.

Kohlstedt, D. L., B. Evans, and S. J. Mackwell (1995), Strength of the lithosphere: Constraints imposed by laboratory experiments, J. Geophys. Res., 100, 17,587-17,602.

Komabayashi, T., K. Hirose, K. Funakoshi, and N. Takafuji (2005), Stability of phase A in antigorite (serpentine) composition determined by in situ X-ray pressure observations, Phys. Earth Planet. Int., 151, 276-289.

Lassak, T. M., M. J. Fouch, C. E. Hall, and E. Kaminski (2006), Seismic characterization of mantle flow in subduction systems: Can we resolve a hydrated mantle wedge?, Earth Planet. Sci. Lett., 243, 632-649.

Levin, V., D. Drozin, and E. Gordeev (2004), Detailed mapping of seismic anisotropy with local shear waves in southeastern Kamchatka, Geophys. J. Int., 158, 1009-1023.

Long, M., and R. van der Hilst (2005), Upper mantle anisotropy beneath Japan from shear wave splitting, Phys. Earth Planet. Int., 151, 13461358 
McKenzie, D. (1979), Finite deformation during fluid flow, Geophys. J. R. Astron. Soc., 58, 689-715.

Mei, S., and D. L. Kohlstedt (2000a), Influence of water on plastic deformation of olivine aggregates 1. diffusion creep regime., J. Geophys. Res., $150,21,457-21,469$

Mei, S., and D. L. Kohlstedt (2000b), Influence of water on plastic deformation of olivine aggregates 2. dislocation creep regime, J. Geophys. Res., 105, 21,471-21,481.

Miller, M. M., T. Melbourne, D. J. Johnson, and W. Q. Sumner (2001), Periodic slow earthquakes from the Cascadia subduction zone, Science, 295,2423

Mizukami, T., S. R. Wallis, and J. Yamamoto (2004), Natural examples of olivine lattice preferred orientation patterns with a flow-normal a-axis maximum, Nature, 427, 432-436.

Mockel, J. R. (1969), Structural petrology of the garnet-peridotite of Alpe Arami (Ticino, Switzerland), Leidse Geol., 42, 61-130.

Nakajima, J., and A. Hasegawa (2004), Shear-wave polarization anisotropy and subduction-induced flow in the mantle wedge of northeastern Japan, Earth Planet. Sci. Lett., 225, 365-377.

Nakajima, J., J. Shimizu, S. Hori, and A. Hasegawa (2006), Shear-wave splitting beneath the southwestern Kurile arc and northeastern Japan arc: A new insight into mantle return flow, Geophys. Res. Lett., 33, L05305, doi:10.1029/2005GL025053.

Obara, K. (2002), Nonvolcanic deep tremor associated with subduction in southwest Japan, Science, 296, 1679-1681.

Okubo, Y., Y. Uchida, M. Taniguchi, A. Miyakoshi, and J. Safanda (2005), Statistical analysis for thermal data in the Japanese Islands, Phys. Earth Planet. Int., 152, 277-291.

Peacock, S. M., and R. D. Hyndman (1999), Hydrous minerals in the mantle wedge and the maximum depth of subduction thrust earthquakes, Geophys. Res. Lett., 26, 2517-2520.

Peacock, S. M., and K. Wang (1999), Seismic consequences of warm versus cool subduction metamorphism: examples from southwest and northeast Japan, Science, 286, 937-939.

Polet, J., P. G. Silver, S. Beck, T. Wallace, G. Zandt, S. Ruppert, R. Kind, and A. Rudloff (2000), Shear wave anisotropy beneath the Andes from the BANJO, SEDA, and PISCO experiments, J. Geophys. Res., 105, $6287-6304$.

Rayleigh, C. B., and M. S. Paterson (1965), Experimental deformation of serpentinite and its tectonic implications, J. Geophys. Res., 70, 39653985.

Reyners, M., D. Eberhart-Phillips, G. Stuart, and Y. Nishimura (2006), Imaging subduction from the trench to $300 \mathrm{~km}$ depth beneath the centra North Island, new zealand, with $\mathrm{V}_{p}$ and $\mathrm{V}_{p} / \mathrm{V}_{s}$, Geophys. J. Int., 165, $565-583$.

Ribe, N. M. (1992), On the relation between seismic anisotropy and finite strain, J. Geophys. Res., 97, 8737-8747.

Rogers, G., and H. Dragert (2003), Episodic tremor and slip on the Cascadia subduction zone: the chatter of silent slip, Science, 300, 1942-1943.

Sacks, I. S. (1984), Subduction geometry and magma genesis, in Explosive Volcanism: Inception, Evolution, and Hazards, pp. 34-46, Natl. Acad Press, Washington, D. C.

Schmidt, M., and S. Poli (1998), Experimentally based water budgets for dehydrating slabs and consequences for arc magma generation, Earth Planet. Sci. Lett, 163, 361-379.

Scholz, C. H. (2002), The Mechanics of Earthquakes and Faulting, 471 pp., Cambridge Univ. Press, New York.

Skemer, P., I. Katayama, and S. Karato (2006), Deformation fabrics of the Cima di Gagnone Peridotite Massif, Central Alpes, Swizerland: Evidence of deformation under water-rich conditions at low temperatures, Contrib. Mineral. Petrol., 152, 43-51.

Smith, G. P., D. A. Wiens, K. M. Fischer, L. M. Dorman, S. C. Webb, and J. A. Hildebrand (2001), A complex pattern of mantle flow in the Lau Back arc, Science, 292, 713-716.
Soyer, W., and M. Unsworth (2006), Deep electrical structure of the northern Cascadia (British Columbia, Canada) subduction zone: Implications for the distribution of fluids, Geology, 34, 53-56.

Spencer, A. (1980), Continuum Mechanics, 183 pp., Longman, London.

Stachnik, J. C., G. A. Abers, and D. Christensen (2004), Seismic attenuation and mantle wedge temperatures in the Alaska subduction zone, J. Geophys. Res., 109, B10304, doi:10.1029/2004JB003018.

Suyehiro, K., et al. (1996), Continental crust, crustal underplating, and lowq upper mantle beneath an oceanic island arc,, Science, 272, 390-392.

Syracuse, E. M., and G. A. Abers (2006), Global compilation of variations in slab depth beneath arc volcanoes and implications, Geochem. Geophys. Geosyst., 7, Q05017, doi:10.1029/2005GC001045.

Takanami, T., I. S. Sacks, and A. Hasegawa (2000), Attenuation structure beneath the volcanic front in northeastern Japan from broad-band seismograms, Phys. Earth Planet. Int., 121, 339-357.

Tamura, Y., Y. Tatsumi, D. Zhao, Y. Kido, and H. Shukuno (2002), Hot fingers in the mantle wedge: new insights into magma genesis in subduction zones, Earth Planet. Sci. Lett., 197, 105-116.

Tsumura, N., S. Matsumoto, S. Horiuchi, and A. Hasegawa (2000), Threedimensional attenuation structure beneath the northeastern Japan arc estimated from spectra of small earthquakes, Tecontophysics, 319, $241-260$.

Turcotte, D. L., and G. Schubert (2002), Geodynamics, 456 pp., Cambridge Univ. Press, New York.

Twiss, R. J. (1977), Theory and applicability of a recrystallized grain size paleopiezometer, Pure Appl. Geophys., 115, 227-244.

Ulmer, P. (2001), Partial melting in the mantle wedge-the role of $\mathrm{H} 2 \mathrm{O}$ in the genesis of mantle-derived 'arc-related' magmas, Phys. Earth Planet. Int., $127,215-232$.

Ulmer, P., and V. Trommsdorff (1995), Serpentine stability to mantle depth and subduction-related magmatism, Science, 268, 858-861.

van der Vorst, H. A. (1992), Bi-CGSTAB: A fast and smoothly converging variant of Bi-CG for the solution of nonsymmetric linear systems, SIAM J. Sci. Comput., 12, 631-644.

van Keken, P. E., B. Kiefer, and S. M. Peacock (2002), High-resolution models of subduction zones: Implications for mineral dehydration reactions and the transport of water into the deep mantle, Geochem. Geophys. Geosyst., 3(10), 1056, doi:10.1029/2001GC000256.

Von Herzen, R., C. Ruppel, P. Molnar, N. Nettles, S. Nagihara, and G. Ekstrom (2001), A constraint on the shear stress at the PacificAustralian plate boundary from heat flow and seismicity at the Kermadec forearc, J. Geophys. Res., 106, 6817-6833.

Wang, K., and K. Suyehiro (1999), How does plate coupling affect crustal stresses in Northeast and Southwest Japan, Geophys. Res. Lett., 26 , $2307-2310$

Zhang, H., C. H. Thurber, D. Shelly, I. Satoshi, G. C. Beroza, and A. Hasegawa (2004), High-resolution subducting-slab structure beneath northern Honshu, Japan revealed by double-difference tomography, Geology, 32, 361-364.

Zhang, S., S. Karato, J. F. Gerald, U. H. Faul, and Y. Zhou (2000), Simple shear deformation of olivine aggregates, Tectonophysics, 316, 133-152.

Zhao, D. D. Christensen, and H. Pulpan (1995), Tomographic imaging of the Alaska subduction zone, J. Geophys. Res., 100, 6487-6504.

S. Karato and I. Katayama, Department of Geology and Geophysics, Yale University, New Haven, CT 06520, USA. (shun-ichiro.karato@yale.edu; ikuo.katayama@yale.edu)

E. A. Kneller and P. E. van Keken, Department of Geological Sciences, University of Michigan, Ann Arbor, MI 48109, USA. (ekneller@umich. edu; keken@umich.edu) 